\title{
Constitución de servidumbres sobre predio propio mediante destinación del padre de familia. Relectura del concepto de "enajenación"*
}

\section{Gian Franco Rosso Elorriaga ${ }^{* *}$}

Resumen. El principio nemini res sua servit iure servitutis y sus consecuencias generan diversas dificultades prácticas en perjuicio de los propietarios. El trabajo descarta a las servidumbres de propietario y la constitución de servidumbres mediante acto jurídico unilateral condicional como vías para su solución. Plantea, en cambio, que esta se logra mediante una relectura del concepto de “enajenación” utilizado por los artículos 88 I c.c.ch. y 938 c.c.col., adecuando su contenido a las exigencias del principio citado, al reconocimiento actual de la propiedad sobre cosas incorporales y a la ampliación que modernamente existe del concepto de predio.

Palabras clave: Nemini res sua servit iure servitutis, destinación del padre de familia, ampliación del concepto enajenación.

La redacción de este artículo ha contado con la ayuda del Fondo Nacional de Ciencia y Tecnología de la República de Chile, en el marco del Proyecto Fondecyt Iniciación n. ${ }^{\circ}$ i I I 40856 , titulado "El régimen jurídico de las servidumbres voluntarias: propuesta de reformulación dogmática a la luz de la funcionalidad actual de las disposiciones del código civil y de la legislación especial", del cual el autor es investigador responsable.

Fecha de recepción: 26 de junio de 2017 . Fecha de aceptación: 8 de junio de 2018 .

Para citar el artículo: Rosso Elorriaga, G. F., "Constitución de servidumbres sobre predio propio mediante destinación del padre de familia. Relectura del concepto de 'enajenación'", Revista de Derecho Privado, Universidad Externado de Colombia, n. ${ }^{\circ}$ 34, enero-junio de 2018, I 79-229. DoI: https://doi.org/I0.1860I/OI 234366.n34.07

* Doctor en Derecho y magíster por la Università degli Studi di Roma Tor Vergata, Roma, Italia. Profesor de Derecho Civil y Derecho Romano en la Facultad de Derecho de la Universidad de los Andes, Chile. Contacto: grosso@uandes.cl 


\section{Constitution of Servitudes over Own-Property by Means of Owner's Destination. Reinterpretation of the "Alienation" Concept}

Авsтract. The principle nemini res sua servit iure servitutis and its effects have created several practical difficulties against the owners. This paper discards as ways of solving these difficulties, the servitude over own-property and the constitution of easements by unilateral-conditional acts. In contrast, this paper states that the solution of such difficulties may be achieved through the reinterpretation of the "alienation" concept included in article $88 \mathrm{I}$ of the c.c.ch. and in article 938 of the c.c.col., in light of the requirements of the abovementioned principle, the recognition of property rights over intangibles and the ample interpretation of the "land" concept existing nowadays.

KeYwords: Nemini res sua servit iure servitutis, destination of the owner, extension of the alienation concept.

Sumario. I. Dificultades prácticas derivadas del principio nemini res sua servit iure servitutis y la destinación del padre de familia. II. Las soluciones posibles: las servidumbres de propietario y la constitución de servidumbres mediante acto jurídico unilateral condicional en particular. III. Crítica y descarte del acto jurídico unilateral condicional como solución en nuestro sistema jurídico. A. No soluciona las dificultades práctico-jurídicas que se presentan antes de la enajenación. B. El carácter de condición de la "ajenidad" resulta discutible. C. El problema del tiempo que una condición puede estar pendiente. Iv. Ampliación del concepto de "enajenación" en materia de destinación del padre de familia.A. Cambios en la propiedad de los predios aceptadas como "enajenación”. B. Cambios en los derechos sobre los predios a los cuales se debe extender el concepto de "enajenación”. v. Relectura ampliada del concepto de "enajenación" en materia de destinación del padre de familia. A. La ampliación del concepto de enajenación tiene por fundamento el principio nemini res sua servit iure servitutis. B. Criterio que determina la constitución del derecho real de servidumbre a través de la destinación del padre de familia. C. Propiedad sobre cosas incorporales en el sistema jurídico chileno y colombiano. D. La ampliación del concepto de predio incluye cosas incorporales. Conclusiones. Bibliografía. 


\section{Dificultades prácticas derivadas del principio nemini res sua servit iure servitutis y la destinación del padre de familia}

Hemos tenido ocasión de tratar con anterioridad el principio nemini res sua servit iure servitutis $^{\mathrm{I}}$, en virtud del cual ninguna cosa propia puede servir a su dueño por derecho de servidumbre. A su respecto, y para los efectos del presente trabajo, nos interesa destacar, a modo de introducción, tres consecuencias relevantes que de él se desprenden.

La primera consiste en que el propietario de dos predios no puede constituir una servidumbre entre estos mediante un acto jurídico unilateral de su parte (o bien entre dos porciones de un mismo predio, hipótesis que debe el lector considerar comprendida en las explicaciones que siguen). Es decir que, por su sola voluntad, a un propietario le es imposible convertirse en dueño de un predio dominante y titular de un derecho real de servidumbre en favor de este y, a su vez, dueño de un predio sirviente gravado con la misma servidumbre de la cual es titular. La razón de esta consecuencia es que el dueño de dos predios no necesita, para servirse de ellos, que se le concedan otros derechos reales distintos al dominio. El propietario usa, goza y dispone de los predios simplemente ejerciendo su ius dominii.

La segunda consecuencia consiste en que todos los servicios que imponga un dueño sobre un predio en favor de otro predio de su propiedad, sea a través de destinaciones materiales o formales ${ }^{2}$, corresponderán a simples situaciones de hecho y no de derecho. Esto es claro, por cuanto se tratará de meros resultados fácticos derivados concretamente del ejercicio de la facultad de disposición material comprendida en la propiedad. Sin embargo, la naturaleza de las referidas situaciones puede mutar a la de relaciones de derecho, convirtiéndose los servicios de hecho en servidumbres. Ello tendrá lugar cuando se produzca una diferenciación en el dominio de los predios; o sea, cuando uno o ambos predios dejen de pertenecer al mismo dueño, lo cual puede ocurrir por la enajenación de uno de los predios a un tercero o bien por la enajenación de ambos predios a dos personas distintas. Asimismo, puede suceder cuando, mediante partición, los predios se adjudiquen a diferentes titulares. Esta modificación en la naturaleza del servicio establecido configuró el modo de constituir servidumbres denominado tradicionalmente por la doctrina como "destinación del padre de familia" (en adelante, DPF), regulado en los artículos 88 I c.c.ch. y 938 c.c.col.

I Rosso Elorriaga, G. F., "Constitución de servidumbres sobre predio propio por acto jurídico unilateral del dueño: destinación formal del padre de familia y relectura del 'servicio aparente", Revista de Derecho Privado, Universidad Externado de Colombia, n. ${ }^{\circ}$ I , 20 I6, I I I-I49.

2 Entendemos por destinaciones formales aquellas que realiza el dueño mediante instrumento público u otras clases de documentos que tengan la virtud, según el ordenamiento respectivo, de ser admitidos a inscripción, subinscripción, anotación o archivo en los registros inmobiliarios respectivos, y que conste en estos. Véase nota precedente. 
Finalmente, una tercera consecuencia es la extinción de las servidumbres por "confusión”. Así como no puede un propietario vincular sus fundos mediante servidumbres, tampoco pueden sobrevivir estas si la propiedad se reúne en un solo titular. De manera que, consolidada la propiedad de los predios en un único dueño, las servidumbres que hubieran existido entre ellos se extinguen. Esta forma de extinción de las servidumbres se regula expresamente en los artículos 885 n. ${ }^{\circ} 3 \cdot^{\circ}$ c.c.ch. y 942 n. ${ }^{\circ} 3$ c.c.col.

Ahora bien, parte de la doctrina advierte que el principio nemini res sua servit iure servitutis y las referidas consecuencias provocan una serie de dificultades prácticas indeseadas a los propietarios, las que se traducen en variados perjuicios para estos. A tales dificultades pasamos revista a continuación 3 .

En relación con las dos primeras consecuencias hay a su vez dos dificultades relevantes que es preciso destacar: la primera, y la más importante, corresponde a la imposibilidad jurídica que habría para los dueños de lograr, por medio de las destinaciones materiales o formales entre sus predios, una reserva de preferencia; la segunda, a la imposibilidad para los mismos de cumplir con las ordenanzas o reglamentos de construcción que en ocasiones exigen servidumbres para el otorgamiento de permisos administrativos de subdivisión, urbanización o construcción.

Respecto de la primera imposibilidad, ya hemos señalado que mediante el solo establecimiento de un servicio entre predios de un mismo propietario no se crea ninguna servidumbre y, por tanto, ningún derecho real en favor o en contra del dueño. La servidumbre solo nacerá si se produce la diferenciación de propiedades por enajenación o partición, a partir del momento en que estas ocurran y cumpliéndose los demás requisitos de la DPF. De modo que mientras esta última no se perfeccione, no existe un derecho real que resulte oponible a otros derechos reales o a derechos personales que eventualmente puedan constituirse después de la destinación sobre uno de los predios en favor de terceros.

En otras palabras, con su destinación material o formal, el propietario no logra crear una relación jurídica oponible por él a futuros titulares de derechos sobre los mismos predios entre los cuales establece el servicio, o bien que le sea oponible por dichos titulares. Es decir que el propietario se ve impedido de dar

3 Las dificultades que se tratarán constituyen una síntesis de los problemas visualizados desde inicios del siglo xx por diferentes autores. Así, Huber, E., Die eigentümerdienstbarkeit, ein Beitrag zu ibrer Rechtfertigung, Bern, Stämpfli, ı902, 9 ss.; Enneccerus, L.; Kipp, T. y Wolff, M., Tratado de derecho civil, Derecho de cosas, t. $3 .^{\circ}$, vol. II, B. Pérez y J. Alguer (trads.), Barcelona, Bosch, I98 I ${ }^{3}, 45$; Cuadrado Pérez, C., La servidumbre de propietario, Madrid, Colegio de Registradores de la Propiedad y Mercantiles de España, 2008, I47 a I 56; Mateo Borge, I., La servidumbre de propietario, Madrid, Marcial Pons, 2000, 82 y 157 a I67; Llácer Matacás, M. R., "La servidumbre sobre finca propia", en Rebolledo Varela, Á. L. (ed.), Tratado de servidumbres, t. II, Navarra, Aranzadi, 20I 33 , 27 I; Arjona Guajardo-Fajardo, J. L., "El derecho de vuelo en nuestro ordenamiento (consideraciones a propósito de unas recientes resoluciones)", Revista Crítica de Derecho Inmobiliario, n. ${ }^{\circ}$ 664, 200 I, 691; García Alguacil, M. J., Consolidación y derechos reales en cosa propia, Granada, Comares, 2002, I05. 
vida a una preferencia, ya sea en su favor o en favor de terceros, frente a derechos que puedan concederse en el futuro respecto de los predios. Incluso, ni siquiera se admite que dicha preferencia quede "reservada" para el caso de que en un tiempo posterior la situación de hecho mute a una de derecho. Veamos algunos ejemplos para la mejor ilustración de la problemática.

Entre los derechos reales que podrían constituirse sobre los predios vinculados por un servicio está el de hipoteca. Supongamos que esta recae sobre el predio sirviente. Es decir, el predio hipotecado, por la destinación de su propietario, tendría la carga de prestar algún servicio al otro del mismo dueño (v.gr., permitir que se conduzca agua por él). Sin embargo, y no obstante haber establecido el propietario el servicio con anterioridad a la hipoteca, aquel no sería oponible al acreedor hipotecario por no tener aún el carácter de derecho real. Y, eventualmente, frente al no pago de la deuda al acreedor hipotecario, podría la finca hipotecada venderse forzosamente en pública subasta. Si bien la transferencia haría nacer la servidumbre, el subastador puede expresar su voluntad contraria en perjuicio del dueño, ahora solo del predio dominante, el cual dejaría de ser tal.

Igualmente, podría ocurrir que en el tiempo intermedio entre la constitución de la hipoteca y la subasta, el dueño del predio sirviente lo venda a un tercero (arts. 24I 5 c.c.ch. y 2440 c.c.col.). Con la tradición respectiva, y por concurrir diferenciación de dominio, el servicio sí se transformaría en servidumbre. ¿Será esta oponible al acreedor hipotecario como asimismo al eventual adquirente en pública subasta? La doctrina predominante se pronuncia negativamente, pues entiende que los derechos reales constituidos sobre la finca hipotecada con posterioridad a la hipoteca no son oponibles al acreedor hipotecario, salvo disposición expresa en contrario ${ }^{4}$. De modo que el dueño del predio dominante nuevamente se quedaría sin ningún derecho a la servidumbre.

En materia de derechos personales de uso y goce sobre uno de los predios, el caso más habitual es el del arrendamiento. Dado que la celebración de este no produciría diferenciación alguna en la propiedad de las fincas, el arrendatario del pre-

4 En este sentido, Cuneo señala que "si no existen reglas que determinen cómo juegan entre sí la hipoteca y la servidumbre, por ejemplo, debe concluirse que no puede gravarse con servidumbre un inmueble hipotecado previamente (naturalmente sin la autorización del acreedor hipotecario)". Si se constituye, al igual que los derechos reales de usufructo, uso y habitación, "es ineficaz cuando la hipoteca ha sido constituida con anterioridad". Cuneo Macchiavello, A., "El usufructo constituido con posterioridad a una hipoteca: su eficacia frente al acreedor", Revista de Derecho y Furisprudencia, 85, 3, I988, i 8 y i i 9 . Asimismo en Tavolari Oliveros, R. (dir.), Doctrinas esenciales, Santiago, Puntolex, 2010, 670 y 673. En el cuanto a la jurisprudencia se ha fallado que el derecho de habitación constituido con posterioridad a la hipoteca se ha extinguido por el solo ministerio de la ley con la adjudicación del inmueble al acreedor hipotecario. CA. de Concepción, 28 enero 20 Io, Ana Manuela Hidalgo Rose Price, Rol I3 I4-2009, CL/ JUR/96I/20IO. Respecto de la inoponibilidad de un usufructo constituido con posterioridad a la hipoteca, CA. de Puerto Montt, 3 I marzo 2004, Sociedad de Profesionales Contables y Compañía Limitada, Rol I 2053, CL/JUR/3 I 89/2004. El mismo criterio se deduce de los artículos Io6 y Io9 inciso $2 .^{\circ}$ del Decreto con Fuerza de Ley 3 de I997, sobre ley general de bancos de Chile. 
dio sirviente no tendría la obligación de soportar el servicio en el predio arrendado, ni el arrendatario del predio dominante tendría la facultad de gozar del servicio.

A continuación, la imposibilidad jurídica para los dueños de lograr una reserva de preferencia a través de las destinaciones materiales o formales entre sus predios trae aparejada la imposibilidad de valorizar sus predios por medio de servidumbres o, por el contrario, de impedir su desvalorización, según sea el caso.

$\mathrm{Al}$ respecto, debe tenerse presente que hay ciertas características ligadas a un bien raíz que llevan a un aumento de su plusvalía. Suelen citarse como ejemplo la existencia de disposiciones que prohíban la instalación de residencias universitarias, locales nocturnos u otras actividades que tendencialmente rompen la tranquilidad de los barrios; o bien que prohíban la construcción en altura (altius non tollendi) en sectores con vista al mar o con otra vista privilegiada, de modo de permitir que las edificaciones que se levanten más atrás mantengan el beneficio. Si dichas disposiciones no han sido establecidas por la autoridad pública, el propietario de un terreno podría conseguir el mismo resultado antes de venderlo por lotes (si lo subdivide), mediante la constitución de servidumbres recíprocas. El que estas sean derechos reales oponibles erga omnes y de vocación perpetua son elementos que proporcionan la confianza necesaria a los adquirentes de los lotes, en orden a que las prohibiciones se respetarán y mantendrán en el tiempo.

El resultado señalado lo alcanzaría el propietario cuando, habiendo establecido material o formalmente las respectivas restricciones como servicios recíprocos, logre enajenar al menos uno de los predios. Esto por aplicación de los artículos 88 I c.c.ch. y 938 c.c.col.

Sin embargo, las expectativas del propietario pueden verse frustradas de muy diversas maneras. Por ejemplo, los bancos a los cuales acude el propietario para financiar su proyecto pueden admitir que las servidumbres incrementarían la tasación del loteo pero, como aún son simples destinaciones y no servidumbres, entender que el valor sigue siendo más bajo. Así, no queriendo asumir las entidades financieras el riesgo de lo que pueda ocurrir en el tiempo intermedio, podrían simplemente negarle al propietario el mutuo de dinero solicitado, o bien solo concederle una suma menor conforme el valor más bajo.

También podría ocurrir que antes que se enajene el primer lote, se constituya un usufructo por voluntad del propietario o en virtud de una resolución judicial, por ejemplo, sobre el sitio que goza de mejor vista al mar. Dado que aún no ha nacido la servidumbre que prohíbe que en este se construya a una altura que impida la vista a los lotes posteriores, el usufructuario podría edificar libremente y con una elevación superior a la dispuesta por el propietario. Al usufructuario le bastaría con el respeto de las normas de urbanismo y construcción en esta materia, pero la prohibición, no siendo aún servidumbre, le sería inoponible.

En cuanto a la segunda imposibilidad, consistente en no poder cumplir con las ordenanzas o reglamentos de construcción cuando exigen el establecimiento de servidumbres para el otorgamiento de permisos administrativos de subdivisión, urbanización o construcción, ello se debe a que, aun cuando el dueño del 
terreno realice todas y cada una de las destinaciones formales entre los distintos lotes o unidades que exijan las normativas respectivas, aquellas no tendrán el carácter de servidumbres, pues estas no pueden ser constituidas mediante acto unilateral voluntario del dueño.

Esta problemática puede entenderse atenuada en los países que regulan la DPF. Esto en razón de que los servicios de hecho establecidos mediante una destinación formal, se transformarán en servidumbre luego de la primera enajenación de uno de los lotes o unidades en que el terreno quedó dividido, por aplicación de los artículos 88 I c.c.ch. y 938 c.c.col. Empero, no significa esto que los problemas se acaben por completo. Así como el propietario unilateralmente efectuó las referidas destinaciones, también unilateralmente podría dejarlas sin efecto. A partir de esta posibilidad surgen una serie de nuevas cuestiones que no tienen aún solución. ¿Puede el propietario dejar sin efecto las destinaciones en el tiempo intermedio entre el acto administrativo que aprobó la subdivisión, urbanización o construcción y la enajenación del primer lote o unidad? De admitirse, ¿queda o no sin efecto el acto administrativo que tuvo como supuesto la existencia de la destinación? (aunque técnicamente lo exigido era una servidumbre).

En relación con la tercera consecuencia del principio nemini res sua servit iure servitutis, que corresponde a la extinción de las servidumbres por confusión, hay dos dificultades prácticas que cita comúnmente la doctrina ante la eventual necesidad futura de que resurja la servidumbre.

La primera es de naturaleza económica. Desaparecida una servidumbre producto de la consolidación de la propiedad, cabe la posibilidad de que esta vuelva en el futuro a separarse. De ocurrir esto, los dueños de los predios podrían tener la voluntad de constituir (o más bien hacer resurgir) la servidumbre extinguida. En tal caso, tendrían que incurrir nuevamente en gastos para alcanzar dicho propósito, entre los cuales se cuentan la contratación de profesionales y el pago de los aranceles e impuestos respectivos.

Esta dificultad, sin embargo, se presenta en países donde no fue recepcionada la DPF o bien que, acogiéndola, desecharon el renacimiento de la servidumbre extinguida por confusión (v. gr., España y Panamá) ${ }^{5}$. Chile y Colombia, en cambio, forman parte de las naciones que acogieron este renacimiento cuando se mantiene la destinación del propietario. Así, los artículos $885 \mathrm{n} .{ }^{\circ} 3 .^{\circ}$ c.c.ch. y 942 n. ${ }^{\circ} 3$ c.c.col. disponen en su inciso segundo que la servidumbre revive en el caso de los artículos 88 y y 938 respectivamente. De manera que, si la destinación sigue vigente, con la nueva enajenación o adjudicación a terceros de uno de los predios, el servicio revive como servidumbre, sin que sea necesario incurrir en

5 Ver, sobre la historia en los códigos de esta institución, Rosso Elorriaga, G. F., "Destinación del padre de familia en las servidumbres", en Basso, M. et al. (ed.), Sistema jurídico romanista y subsistema jurídico latinoamericano, Liber discipulorum para el profesor Schipani, Bogotá, Universidad Externado de Colombia, 2013, 952 y 953. 
nuevos costos. De manera que esta particular dificultad no se presentaría en nuestros sistemas.

La segunda dificultad relacionada con la extinción de las servidumbres por confusión está vinculada al problema ya tratado de la reserva de preferencia. Puede suceder que, luego de la consolidación del dominio, el propietario de los predios, en vez de transferir o transmitir el dominio, de uno o ambos, como en el caso anterior, constituya un derecho real distinto al dominio o conceda un derecho personal sobre uno de los fundos. De seguirse la doctrina tradicional, el otorgamiento de estos derechos no sería un acto de enajenación que separe la propiedad de las fincas y, por tanto, no reviviría la servidumbre. Incluso, no se produciría el resurgimiento de esta a pesar de que la destinación hubiera sido formal y figurara en el registro inmobiliario. Todo lo cual se traduce una vez más en que el servicio establecido entre los predios sería inoponible por su propietario al titular del nuevo derecho real o personal, o viceversa.

De la revisión efectuada en las líneas precedentes de las dificultades prácticas que el principio nemini res sua servit iure servitutis y sus consecuencias generarían para los propietarios se puede concluir que, en definitiva, el problema esencial es uno solo: la "oportunidad" en que se transforman en servidumbre los servicios que el propietario ha establecido material o formalmente entre sus predios. $\mathrm{Y}$ dicha oportunidad correspondería al momento en que tiene lugar la separación de la propiedad de estos últimos, mediante la enajenación o adjudicación de uno de ellos o de ambos, a terceros. De manera que la solución a las referidas dificultades se encontraría en alterar dicha oportunidad, logrando que esta coincida con el instante de la destinación.

En los acápites que siguen daremos cuenta de las denominadas servidumbres de propietario y de la constitución de servidumbres mediante acto jurídico unilateral condicional, en cuanto mecanismos institucionales desarrollados por la doctrina que, aunque diversos, permitirían alcanzar la solución antes señalada. Asimismo, expondremos las razones que nos conducen a creer que jurídicamente no pueden o no deben adoptarse como vías de superación del problema que enfrentamos.

A continuación, entendiendo que la oportunidad en que los servicios establecidos por el propietario entre sus predios se transforman en servidumbres es el instante de la "enajenación" de uno de uno de ellos o de ambos a personas diferentes, buscaremos por el contrario la solución al problema por la vía del análisis de este concepto presente en los artículos 88 I c.c.ch. y 938 c.c.col. En primer lugar, constatando la ampliación de su sentido y alcance de que ha sido objeto, con el fin de darle correcta aplicación en materia de DPF; y, en segundo lugar, desarrollando una ulterior ampliación del término "enajenación" en este ámbito, por medio de una relectura del mismo que se adecue realmente a las exigencias del principio nemini res sua servit iure servitutis; al reconocimiento actual de la propiedad sobre cosas incorporales, y a la ampliación que modernamente existe del concepto de predio. 


\section{Las soluciones posibles: las servidumbres de propietario y la constitución de servidumbres mediante acto jurídico unilateral condicional en particular}

Las "servidumbres de propietario" nacen originalmente en países cuyos códigos no contemplaban la DPF. Esta omisión importaba que los problemas derivados de la aplicación del principio nemini res sua servit iure servitutis fueran aún más perjudiciales para los dueños, pues ni siquiera en virtud de una diferenciación de dominio las destinaciones materiales o formales que hubieran efectuado entre predios propios se convertían en servidumbres. En todo caso, tampoco debió existir mucho entusiasmo por consagrar la institución de la DPF, dados los problemas que esta igualmente presentaba.

La institución de la "servidumbre de propietario" se caracteriza en lo fundamental por no exigir el requisito de la "ajenidad" para su nacimiento; o sea, puede constituirse una servidumbre entre predios propios ${ }^{6}$. La servidumbre en este sistema es por tanto un derecho real entre predios, a secas, y no entre predios de distinto dueño. Como consecuencia de ello, el propietario de dos predios puede constituir y adquirir el derecho real de servidumbre activa sobre uno de ellos y, a la vez, someterse al gravamen correlativo impuesto al otro predio. Todo lo anterior mediante un acto jurídico unilateral, por lo que la servidumbre nace entonces con la celebración de este o con la inscripción de la servidumbre en el registro inmobiliario respectivo según sea el caso.

Lo expresado se traduce en que la "servidumbre de propietario" permite al dueño de dos predios tener en paralelo la titularidad de un derecho real de servidumbre en favor de uno de ellos, con la carga correlativa para el otro aunque también le pertenezca. La admisión de esta posibilidad se traduce en que, frente al nacimiento de otros derechos reales a posteriori (como el de hipoteca) o de derechos personales (como el de arrendamiento), la servidumbre constituida unilateralmente les sería oponible a sus titulares (como al acreedor hipotecario o el arrendatario), o bien sería oponible por estos al dueño. Así las cosas, el problema de la "oportunidad" que generaría la DPF resulta superado por completo, al sustituirse una eventual transformación futura de la destinación de hecho en servidumbre, por un efectivo nacimiento de esta en el presente.

De manera correlativa, no existiendo "ajenidad", la extinción de la servidumbre por consolidación no tiene lugar, pues la reunión del predio dominante y del predio sirviente en unas mismas manos no impide la existencia de la servidumbre, requiriéndose expresa declaración del dueño respecto a su extinción.

Sin embargo, todo lo anterior se logra simplemente dejando sin efecto el principio nemini res sua servit iure servitutis, con la creación de una institución en que excepcionalmente no tiene aplicación. Por lo mismo, requiere de la inter-

6 Sobre esta institución, véase Rosso, Constitución de servidumbres, cit., I 20 ss. 
vención del legislador, en orden a modificar la configuración legal de las servidumbres. De no producirse, continúan evidentemente rigiendo de manera plena las disposiciones generales de nuestros códigos civiles, dentro de las cuales no tiene cabida una tal excepción. Baste solo tener a la vista la definición de servidumbre de los artículos 820 c.c.ch. y 879 c.c.col., cuyo texto expresamente alude a "predio de distinto dueño". Por lo mismo, la admisión de la "servidumbre de propietario" solo por vía interpretativa, como ocurrió en Alemania, resulta muy difícil, pues precisamente en este país colaboró con la doctrina y la jurisprudencia el hecho de que el parágrafo iо 8 no hiciera referencia explícita al requisito de la "ajenidad" en la definición de servidumbre. Adicionalmente, el sistema adquisitivo de servidumbres del вGв no contempla la DPF, de modo que ninguna solución interpretativa a los problemas planteados podía lograrse por medio esta última institución.

La alternativa a la "servidumbre de propietario" ha sido la "constitución de servidumbres por acto jurídico unilateral condicional", la cual ha tenido particular desarrollo en España. Precisamente, la doctrina y la jurisprudencia han debido enfrentar en este país, al igual que nosotros, un código civil que recoge la característica de la "ajenidad" entre los predios, conforme la definición de servidumbre consagrada en el artículo 530. Pero además, un código civil que también contempla la DPF en el artículo 54I, prefiriendo los autores y tribunales apartarse de esta figura en razón de su configuración legal, la cual llevaría inicialmente a las consecuencias negativas ya vistas en el acápite anterior. En términos simples, se ha preferido desarrollar una interpretación de las disposiciones del código civil paralela a la DPF, a fin de eludir a esta. E incluso, dada la especial división político-territorial en España, en los códigos o leyes civiles impulsados por las comunidades autónomas, aprovechando que se trata de una intervención legislativa ex novo, no se ha replicado en algunos casos el modelo del código civil común, acogiéndose la "servidumbre de propietario"7. Así las cosas, curiosamente, España resulta hoy ser ejemplo en los dos caminos de solución referidos.

En este contexto, y en lo que se refiere al código civil español, la mayoría de la doctrina española, seguida además por la jurisprudencia, está de acuerdo en que es posible la constitución unilateral de servidumbres inscrita en el registro de propiedad por parte del propietario pero bajo condición legal suspensiva ${ }^{8}$.

7 P. ej., art. 566-3.I del código de Cataluña, art. 87.I de la Ley de Galicia.

8 García García, J. M., "Comentario a sentencia del TS de 2 I de octubre de i976", Revista Crítica de Derecho Inmobiliario, 529, I978, I 255 y I 256. Citando la doctrina española favorable, con revisión de la doctrina de García, CuAdrado, La servidumbre de propietario, cit., I 78 a I82, I 98 ss.; y expresando su conformidad con esta postura de un modo explícito en i88, i 90 y 2 I4. Asimismo, Díaz Fuentes, A., Servidumbres, serventías y relaciones de vecindad, Barcelona, Bosch, 2004, 56 y 57; Rebolledo VArela, Á. L., Tratado de servidumbres, t. I, Navarra, Aranzadi, 20I $3^{3}$, 54; Jordano Fraga, F., "Prehorizontalidad y servidumbre de propietario", Revista de Derecho Notarial, I I3-I I4, I98I, I 73, 223 y 224. 
Es decir que el propietario de dos fincas puede constituir mediante acto unilateral servidumbres entre los inmuebles de su propiedad e inscribirla en el registro inmobiliario. Dicha constitución, sin embargo, quedaría sujeta a la condición suspensiva legal consistente en que el dominio de uno de los predios pase a manos de un tercero. Claro, porque como ya anunciáramos, el artículo 530 c.c.es. establece, al igual que nuestros artículos 820 c.c.ch. y 879 c.c.col., que los inmuebles deben pertenecer a distintos propietarios. De manera que la servidumbre entre predios de un mismo dueño, por el acto unilateral de este, no podría nacer. El gravamen quedaría en suspenso hasta que se cumpliera la condición legal consistente en la "ajenidad" de los fundos; esto es, hasta que se produzca la separación de la propiedad en dueños diferentes, sea por la enajenación de uno de ellos o de ambos a diferentes personas, sea por la transmisión de uno o de ambos a dos o más herederos.

Nótese que, por esta vía de solución, el acto que da vida a la servidumbre es exactamente el mismo que en la DPF. Igualmente, mientras no tenga lugar la separación de dominio, la servidumbre aún no existe como derecho real y gravamen correlativo. La diferencia estriba, y es lo que convertiría a la constitución unilateral condicional en alternativa de solución, en la consecuencia que por regla general produce toda condición cumplida: la retroactividad de sus efectos. Así entonces, recurriendo a esta, se debe concluir que la constitución de la servidumbre no se produjo en el momento de la enajenación o transmisión, sino en la fecha en que tuvo lugar la celebración del acto unilateral9.

Es este efecto retroactivo de la condición el elemento esencial de la solución, pues es en razón de él que las servidumbres constituidas resultarían oponibles a cualquier derecho que se haya constituido con posterioridad al acto jurídico unilateral. Se trataría entonces de servidumbres que desde el momento de la celebración de este acto por parte del propietario quedarían en estado latente, lo que sería por todos conocido luego de su inscripción en el registro, las cuales cobran vida en un momento futuro incierto: cuando se produzca la separación en la titularidad de la propiedad.

Desde un punto de vista legal, la admisión de la constitución unilateral condicional se fundamenta en el texto del artículo 536 c.c.es., de conformidad con el cual "las servidumbres se establecen por la ley o la voluntad de los propietarios". Luego, la voluntad del propietario sería uno de los modos que la ley expresamente admite de constitución de servidumbres ${ }^{\mathrm{Io}}$, aunque bajo la condición de que tenga lugar la "ajenidad”, a la luz de la definición del artículo 530.

Esta doctrina interpretativa exige, para su mejor comprensión, confrontarla con el problema de la distinción entre título y modo, que son las exigencias de nuestro sistema adquisitivo, pero no las del sistema español. Según el texto del

9 Cuadrado, La servidumbre de propietario, cit., I93.

Io García García, "Comentario a sentencia”, cit., I 258. 
artículo 609 c.c.es., solo se requiere de modo para la adquisición de derechos reales por contrato. De manera que no hace falta la tradición para la adquisición de un derecho real cuando se celebra otro acto jurídico inter vivos distinto a un contrato ${ }^{11}$. En consecuencia, si se constituye una servidumbre mediante contrato, es necesaria la tradición; si el título es distinto, no se exige ${ }^{\mathrm{I} 2}$. Luego, la discusión acerca de si toda adquisición exige la concurrencia de un título y de un modo no se ha presentado. Incluso más, "la inscripción en el Registro es [...] algo distinto y aparte de la tradición" ${ }^{13}$.

En este contexto es fácil concluir que si los artículos 537 y 539 c.c.es. disponen que las servidumbres se adquieren en virtud de título, y este es diferente a un contrato, como sería el caso de un acto jurídico unilateral condicional, la servidumbre nace con el mismo acto, aunque sus efectos queden en suspenso hasta el cumplimiento de la condición.

Ahora bien, se distinga o no entre título y modo de adquirir, el fundamento de la constitución unilateral de servidumbres tiene de todas maneras un problema desde el principio. En efecto, resulta claro que la voluntad del propietario de los fundos no es causa suficiente para que nazca una servidumbre ni tampoco para adquirir el derecho real respectivo, sea este en favor del predio que resta en poder del propietario original o del predio que adquiere el tercero. De manera que la constitución de la servidumbre no cabe en la alternativa "establecimiento por la voluntad de los propietarios" del artículo 536 c.c.es. Asimismo, también es claro que dicho nacimiento y adquisición tendrían necesariamente lugar por disposición de la ley.

Es más, la interpretación que comentamos ha sostenido que el acto unilateral queda sujeto no a una conditio facti, sino a una conditio iuris ${ }^{\mathrm{I} 4}$. Esto significa que el hecho futuro e incierto del cual pende el nacimiento del derecho de servidumbre no es impuesto por el propietario, sino por la ley a través del artículo 530 c.c.es. (que consagra la ajenidad de los fundos). Luego, si en vez de mirar la cuestión desde el punto de vista de la naturaleza jurídica de la condición (facti o iuris), se mira desde el punto de vista de los modos de adquirir los derechos reales, se concluye que el único modo que podría operar en este caso es la ley. Por lo demás, excluida la voluntad del propietario, es la única alternativa que queda de las señaladas por el artículo 536 c.c.es. El fundamento entonces de la interpretación en comento resulta desde un principio debilitado, si no eliminado.

Junto a las alternativas precedentes, es interesante citar una solución ecléctica, que intentaría recoger las bondades y superar las dificultades de ambas. El código del derecho foral de Aragón regula la "servidumbre sobre cosa propia" (o sea, servidumbre de propietario) en el artículo 564 y la "constitución por signo

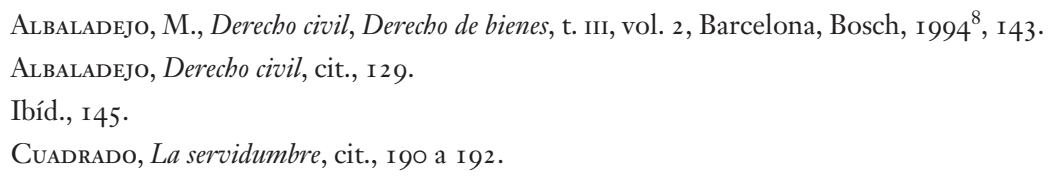


aparente" (denominación moderna de la "destinación del padre de familia”) en el artículo 566. Respecto de la primera, la disposición establece que queda "su efectividad subordinada a que la finca dominante o la sirviente cambien de titularidad”. Luego, no se advierte a simple vista qué diferencia podría tener con la DPF, la que se caracteriza precisamente por la constitución de la servidumbre al momento de la enajenación o adjudicación de uno de los predios ${ }^{15}$. A la pregunta por la diferencia entre ambas instituciones se contesta que "en la servidumbre en finca propia [...] la inscripción en el Registro de la Propiedad determinará su rango. Por lo que su eficacia, que se dará en el momento de la enajenación de una de las fincas o de una de las partes segregadas, se retrotraerá al momento de la inscripción"; mientras que "en la servidumbre constituida por signo aparente [...] la constitución y eficacia se darán en el mismo momento, es decir cuando se enajene una de las fincas o una de las partes segregadas" ${ }^{6}$. En otras palabras, al decir de la doctrina, el citado artículo 564 habría consagrado en Aragón una suerte de constitución por acto jurídico unilateral bajo condición suspensiva expresa, o bien una destinación del padre de familia con efecto retroactivo.

Cualquiera sea la naturaleza que se le atribuya, se trataría de una solución que importa una intervención del legislador, con la finalidad de modificar la "oportunidad" a partir de la cual el servicio establecido por el legislador comienza a producir efectos como servidumbre. La inscripción en el registro inmobiliario llevaría a que los terceros se vieran afectados por el efecto retroactivo; es decir, a que les resultara oponible el servicio en calidad de servidumbre.

\section{Crítica y descarte del acto jurídico unilateral condicional como solución en nuestro sistema jurídico}

Dado que la "servidumbre de propietario" requeriría indefectiblemente de intervención legal, solo cabe preguntarse si podríamos en Chile y Colombia, conforme a las disposiciones vigentes de los respectivos códigos civiles, acudir a la interpretación del acto jurídico unilateral condicional desarrollada en la madre patria.

La admisión de esta figura permitiría ciertamente superar dos dificultades que la DPF presenta. La primera, que esta tradicionalmente se ha entendido aplicable solo a destinaciones materiales, lo que excluiría a las destinaciones formales,

I 5 Expresamente señala que si el único dueño puede proceder a la constitución de la servidumbre -aunque la misma sería ineficaz hasta la enajenación-, no tendría mucho sentido contemplar la constitución por mantenimiento del signo aparente Alonso Pérez, M. T., "Constitución y extinción de las servidumbres", en BAyod, C. (ed.), Derecho civil patrimonial aragonés, Zaragoza, Institución "Fernando El Católico" (c.s.I.c.), 20 I3, I 70.

i6 Bellod Fernández de Palencia, E., "Servidumbres: concepto, clases, caracteres, contenido de las servidumbres", en BAYOD, C. (ed.), Derecho civil patrimonial aragonés, Zaragoza, Institución "Fernando El Católico" (c.s.i.c.), 20I3, p. i40. En el mismo sentido, Peralta Jiménez, C., Las servidumbres en Aragón. Disponible en: http://www.economistjurist.es/articulos-juridicosdestacados/las-servidumbres-en-aragon/ [Consultado 5 enero 2018]. 
como sería un acto jurídico unilateral. No obstante ello, en otro trabajo hemos aclarado que la interpretación restrictiva de los artículos 88 I c.c.ch. y 938 c.c.col. que limita las destinaciones al propietario es simplemente un equívoco entendimiento que debe descartarse, de modo que la dificultad no existe, o bien se encuentra superada ${ }^{17}$. Se debe por tanto partir de la base de que la DPF puede ser material o formal. Luego, aceptada la destinación formal del propietario, la supuesta diferencia entre la DPF y el acto jurídico unilateral condicional desaparece.

En todo caso, la verdadera razón de por qué se intenta descartar la destinación formal del padre de familia (interpretación amplia del artículo 54 I c.c.es.), y que lleva en España a que se prefiera la doctrina del acto unilateral condicional, dice relación con la segunda dificultad que presentaría la DPF: esta produciría efectos hacia el futuro, con lo cual la servidumbre resultaría inoponible a los derechos constituidos en el tiempo intermedio. En cambio, gracias al efecto retroactivo propio de las condiciones cumplidas, la servidumbre constituida mediante acto jurídico unilateral condicional sí sería oponible. Esto último debido a que, llegado el día del acto de enajenación, se debiera entender retrotraído el nacimiento de la servidumbre a la fecha de la celebración del acto unilateral constitutivo. De esta manera, la servidumbre respectiva habría nacido antes que cualquier derecho real o personal relativo a la cosa, constituido o concedido con posterioridad al acto jurídico unilateral del propietario, y en precedencia a la enajenación de uno de los predios.

A nuestro entender, la interpretación de la constitución de servidumbre mediante acto jurídico unilateral bajo la condición suspensiva de la enajenación futura es una postura jurídicamente atractiva, pero dogmáticamente imperfecta. Asimismo, es una salida cómoda, pues elude en definitiva una construcción doctrinaria a partir de la raíz jurídica de la problemática, como es el principio nemini res sua servit iure servitutis. Veamos acto seguido las razones de su imperfección.

\section{A. No soluciona las dificultades práctico-jurídicas que se presentan antes de la enajenación}

La solución en comento es cimentada sobre la base de atribuir el carácter de conditio iuris a uno de los requisitos esenciales de la institución de las servidumbres, como es la "ajenidad" de los predios; esto es, que predio dominante y sirviente pertenezcan a distintos dueños. De manera que la condición se cumple cuando se produce la diferenciación de propiedades, lo que puede ocurrir por vía de enajenación o por vía de transmisión a dos o más herederos (salvo que ambos predios sean adjudicados al mismo heredero) o legatarios. Mientras tal enajenación o transmisión no ocurra, la condición se encuentra pendiente, el efecto retroactivo no tiene lugar y la servidumbre no se entiende constituida.

I 7 Ver nota I. 
Conforme a lo anterior, la servidumbre sujeta a condición es inoponible a los derechos reales que se constituyan sobre la cosa o a los derechos personales que se concedan respecto de la cosa. Incluso más, dichos derechos pueden no solo haber nacido antes de la enajenación o transmisión, sino incluso ya haberse extinguido cuando estas tengan lugar. De modo que puede perfectamente ocurrir que ni en su nacimiento ni durante su vigencia dichos derechos se vieran limitados o favorecidos por la servidumbre pendiente.

Pensemos, por ejemplo, en el citado caso de la servidumbre altius non tollendi establecida por el propietario sobre uno de sus predios que tiene vista al mar, sobre el cual se constituye un usufructo. Decíamos que, por no haber nacido la servidumbre, el usufructuario perfectamente podía construir sobre la altura fijada por el dueño. Evidentemente, después de haberse edificado y obstruido la vista, no solo ya no tiene sentido que el servicio se convierta en servidumbre con la enajenación de uno de los predios sino que, peor aún, puede ser la construcción y la obstaculización de la visual, la causa de que nunca el propietario logre vender uno de los predios, o bien lo haga por un precio muy inferior al originalmente proyectado.

Asimismo, perfectamente el propietario podría establecer un servicio de paso sobre uno de sus predios en favor de otro para facilitar el acceso, por ejemplo, a la carretera, y luego arrendar por unos años el predio favorecido con el paso, sin indicación alguna de dicho servicio en el contrato de arrendamiento. Luego, el arrendatario, al intentar pasar por el predio supuestamente gravado, es expelido por el dueño, alegando este que la servidumbre aún no existe ${ }^{18}$. Con ello obliga al arrendatario a tomar el camino más largo o difícil hacia la carretera, a pesar de que había sido justamente el servicio de paso supuestamente constituido lo que le había llevado a tomar en arriendo el inmueble.

Dado que la retroactividad no soluciona todas las dificultades mientras la propiedad de los predios no se divida, las comunidades autónomas españolas así como otras legislaciones se han inclinado en el momento de una intervención legislativa por la institución de la "servidumbre de propietario".

\section{B. El carácter de condición de la "ajenidad" resulta discutible}

Para que produzca el efecto retroactivo que permitiría darle vida a la servidumbre desde la fecha misma de su establecimiento por el dueño, para la interpretación

I 8 Hacemos presente que la doctrina clásica ha excluido de la constitución mediante destinación del padre de familia a las servidumbres de tránsito, por calificar el legislador a estas de discontinuas, en circunstancias en que los artículos 88 I c.c.ch. y 938 c.c.col. exigen que el servicio sea "continuo". Si así fuera, jamás la separación de la propiedad daría lugar a una servidumbre de tránsito a partir de un servicio de paso establecido previamente por el propietario. Por nuestra parte, dicha interpretación la consideramos equívoca. Véase Rosso Elorriaga, G. F., "Las servidumbres discontinuas pueden adquirirse por 'destinación del padre de familia'. Reinterpretación del artículo 88 I del Código Civil”, en Barría, M. (ed.), Estudios de derecho civil XI, Santiago, Legal Publishing, 2016, 353-374. 
que tratamos ha sido necesario convertir un requisito legal (arts. 820 c.c.ch. y 879 c.c.col.) en condición. Sin embargo, esta asimilación es en sí misma discutible pues aceptarla importa admitir que todo elemento establecido por la ley constituye la modalidad denominada condición. En otras palabras, la ley se convierte en la fuente por excelencia de las condiciones, resultado que nos parece absurdo.

La regla general es que los actos jurídicos produzcan efectos desde que se cumplan los requisitos exigidos por la ley; o sea, hacia el futuro, y no con efecto retroactivo, salvo que el legislador expresamente disponga otra cosa. Algunos ejemplos para ilustrar la cuestión. Si se celebra un contrato de compraventa sin indicación del precio, y solo en fecha posterior se completa el acto, agregándosele el precio, ¿se entiende que el contrato nació con el primer acto en virtud del efecto retroactivo de la conditio iuris consistente en la concurrencia de cosa y precio, o solo cuando se cumplió con la concurrencia del elemento esencial del precio? O bien, si el contrato de compraventa fue celebrado a través de instrumento privado, pese a que se trate de una cosa inmueble, ¿produce efecto retroactivo el otorgamiento posterior de la escritura pública, que debiera considerarse una conditio iuris? Por último, si se vende un bien embargado sin autorización judicial, y con posterioridad se obtiene esta, ¿se retrotraen los efectos de esta autorización a la fecha de la venta anterior, por tratarse de una conditio iuris, o solo serán válidas las ventas a contar de la fecha de la autorización? (art. I 464 n. 4 c.c.ch. y I 52 I, $3 .^{\circ}$ c.c.col.).

Nos parece que respecto de los tres ejemplos propuestos en precedencia no existirá dudas en el lector en cuanto a que el requisito legal no puede considerarse una condición, ni menos que, una vez cumplida, produzca efectos retroactivos. Los actos, no mediando otra disposición del legislador, producirán efectos desde que se perfeccionan y hacia el futuro.

Lo expresado ratifica por qué la idea misma de conditio iuris resulta confusa, siendo difícil la distinción entre los requisitos legales verdaderamente constitutivos de condición y aquellos que no.

\section{El problema del tiempo que una condición puede estar pendiente}

En nuestro sistema jurídico, la teoría de la constitución de servidumbre por acto unilateral sujeto a condición suspensiva debe enfrentar un problema de difícil solución: el término máximo por el cual una condición puede estar pendiente.

La no presencia en el código de Bello de una disposición que resuelva expresamente la cuestión desembocó en un histórico debate acerca de la aplicación o no de un plazo de caducidad a las condiciones pendientes, que perdura hasta nuestros días. Las alternativas tradicionales a la luz del texto del código civil han sido tres: i) aplicar por analogía los artículos 739 c.c.ch. y 800 c.c.col., que establecen actualmente que la condición para la restitución en materia de fideicomiso se tendrá por fallida transcurridos cinco o treinta años respectiva- 
mente ${ }^{\mathrm{I} 9}$; ii) aplicar el mayor plazo de prescripción que contempla el código civil, que hoy en Chile es de diez años ${ }^{2 \circ}$, el cual coincide con el mayor plazo general para todos los efectos según lo ratifica el artículo 962 (descartando la aplicación del artículo 739), la cual en todo caso no tiene aplicación en Colombia (pues el artículo rorg establece aún un plazo de treinta años, lo que ratificaría más bien recurrir al artículo 8oo); y, iii) no imponer plazo alguno de caducidad para que se verifique una condición indeterminada, dada la omisión del código civil y la naturaleza precisamente no determinada de esta modalidad ${ }^{21}$. Adicionalmente, la Ley 5 I de r9r 8 permitió en Colombia una cuarta posibilidad, al establecer su artículo 23 en materia de opción que la condición se tiene por fallida si tarda más de un año en cumplirse ${ }^{22}$.

La posición dominante, como se ve, descarta la no aplicación de un plazo, discutiéndose más bien acerca de cuál sería el término que debiera aplicarse. Así las cosas, la servidumbre constituida por acto jurídico unilateral entre predios propios bajo la condición de que se enajene o adjudique uno de ellos a un propietario diferente, a lo más podría estar pendiente en Chile diez años (doctrina y jurisprudencia mayoritaria ${ }^{23}$ ) y en Colombia treinta años (doctrina minoritaria),

i 9 En Chile, Ducci Claro, C., Derecho civil, Parte general, Santiago, Jurídica de Chile, Santiago, 20104, n. ${ }^{\circ}$ 402, p. 370; Larraín Ríos, H., Teoría general de las obligaciones, Santiago, LexisNexis, 2005, 68. y 69; Claro Solar, L., Explicaciones de derecho civil chileno y comparado, De las obligacio-

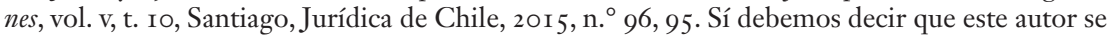
inclinaba por esta solución, por coincidir la regla del fideicomiso con el término más largo de prescripción, por lo que la consideraba una regla general. De modo que, habiéndose reducido en Chile el plazo a 5 años, podría entenderse modificada la opinión. En Colombia, Ospina Fernández, G., Régimen general de las obligaciones, Bogotá, Temis, I978, n. ${ }^{\circ} 360,247$ y 248.

20 Alessandri Rodríguez, A. y Somarriva Undurraga, M., Tratado de las obligaciones, ampliada y actualizada por Antonio Vodanovic Haklicka, Santiago, Jurídica de Chile, 200 I $^{2}$, n. ${ }^{\circ} 324,248$ a 249; Abeliuk Manasevich, R., Las obligaciones, t. I, Santiago, Legal Publishing, $2014^{6}{ }^{6}$ n. ${ }^{\circ}$ 547, 6i6 a 6i 9; Ramos Pazos, R., De las obligaciones, Santiago, LexisNexis, 2004, I 35 y i 36 ; Barcia Lehmann, R., Lecciones de derecho civil chileno, De la teoría de las obligaciones, t. III, Santiago, Jurídica de Chile, 20 io, n. ${ }^{\circ}$ Io6, 36 ; VIAL Del Río, V., Teoría general del acto jurídico, Santiago, Jurídica de Chile, 201 I $,{ }^{\circ}{ }^{\circ} 233,339$ y 340.

2 I En Chile, Solís de Ovando, J., "De la caducidad de las condiciones", Revista de Derecho y furisprudencia, 37, I940, I. ${ }^{a}$ parte, 24 ss. Podríamos citar en esta posición también a Meza Barros, R., Manual de derecho civil, De las obligaciones, Santiago, Jurídica de Chile, 20099 , n. ${ }^{\circ} 78,5^{2}$ y 53, quien sostiene que no se encuentra establecido un plazo máximo legal pero, antes de aplicar los artículos 739 o 962, el plazo deberá ser fijado por el juez, interpretando la voluntad o las circunstancias que dan origen a la obligación. De modo que, en lo que nos interesa, habría en definitiva igualmente un término dentro del cual se debe cumplir la condición.

22 Opta por esta alternativa y rechaza la aplicación de los 30 años del artículo 800 c.c.col. y de los Io años de la prescripción, Velásquez Gómez, H. D., Estudio sobre obligaciones, Bogotá, Temis, 2010, n. ${ }^{\circ} 96.2$, I 7 I a I 72 .

23 Sin perjuicio de la tendencia jurisprudencial histórica, en un caso en que se discutió un permiso de uso de una servidumbre de oleoducto por un tercero otorgado bajo condición suspensiva indeterminada, en causa Rol n. ${ }^{\circ} \mathrm{C}-2885$-20 Io seguida ante el I4. ${ }^{\circ}$ Juzgado Civil de Santiago, expresó el tribunal en el considerando séptimo del fallo de 7 de marzo de 20 I 2 : "cabe expresar que ha transcurrido el plazo máximo de diez años previsto por el legislador para los efectos de que se consoliden las relaciones jurídicas, lo anterior a fin de dar concreción al principio de certeza 
transcurridos los cuales deberá considerarse la condición fallida. Esto significaría que la enajenación o adjudicación posterior a estos términos no generarían el efecto constitutivo de la servidumbre.

Evidentemente un resultado como este no es posible de aceptar. La destinación efectuada por el propietario en virtud del ius dominii mantendrá su vigencia mientras el mismo dueño no exprese voluntad contraria. Es inimaginable que una servidumbre constituida unilateralmente por el propietario entre predios que le pertenecen (incluso inscrita), y no obstante el propietario no la haya dejado sin efecto, pierda su valor constitutivo, aunque aún no haya tenido eficacia, por el mero transcurso del tiempo. Nótese que si así fuera, y dado el carácter unilateral del acto, el propietario podría y tendría que estar renovando la servidumbre continuamente hasta que se cumpla el hecho condicional.

Más absurdo sería si se tratara de un proyecto de subdivisión, loteo o de copropiedad (campo en el cual principalmente se presenta la cuestión que tratamos), aprobado por resolución de un órgano administrativo, y que conllevase servidumbres forzosas entre las distintas partes, lotes o unidades del predio. ¿Quedaría la resolución administrativa sin efecto por haber fallado la condición? ¿Significa que ya no existe ni subdivisión, ni loteo, ni copropiedad inmobiliaria por faltar el requisito habilitante para el acto administrativo? Si la respuesta es positiva y un tercero compra uno de los lotes o unidades con posterioridad al tiempo que se considere fallida la condición según la posición que se adopte, ¿sería nulo el acto por falta de objeto? (pues los lotes o unidades no existirían jurídicamente al haber quedado sin efecto la resolución).

Considerar que la constitución de servidumbre por acto jurídico unilateral del propietario queda sujeta a la condición suspensiva de la ajenidad importa la aplicación de todos los efectos que derivan de una condición. Y así como se pretende gozar de las ventajas que produce la condición cumplida, como es la retroactividad de los efectos, habrán de aceptarse también los defectos, como es la imposibilidad de que una condición se mantenga indefinidamente pendiente en el tiempo, debiendo considerarse fallida si no tiene lugar dentro de cierto lapso. Las consecuencias absurdas que esto último genera para la interpretación que criticamos nos llevan a su rechazo, confirmando de paso que no estamos ni podemos estar frente a una verdadera condición.

Las dificultades revisadas en precedencia que presenta en nuestros sistemas jurídicos la constitución de servidumbres bajo la idea de la conditio iuris claramente dan cuenta de que no resulta finalmente adecuada en la práctica.

jurídica que debe infundir el ordenamiento jurídico". El fallo fue confirmado por la Corte de Apelaciones y la Corte Suprema. Ver CS. I 7 de septiembre de 2014, Handels con Sociedad Nacional de Oleoductos (SONACOL), Rol I 4579-2OI3, VLEX-5286909i 8. 


\section{Ampliación del concepto de "enajenación" en materia de destinación del padre de familia}

\section{A. Cambios en la propiedad de los predios aceptados como "enajenación"}

Señalábamos al término del acápite i que el problema esencial de las dificultades prácticas asociadas al principio nemini res sua servit iure servitutis y sus consecuencias era la oportunidad en que los servicios establecidos por el propietario entre sus predios se transforman en servidumbres, y que este correspondía al instante de la "enajenación”. De ahí que abordaríamos la superación de aquellas a través de la interpretación de este concepto, presente en los artículos 88 I c.c.ch. y 938 c.c.col.

Como se recordará, estos artículos señalan que subsiste el servicio establecido entre dos predios por su único propietario con el carácter de servidumbre cuando dicho propietario "enajena" uno de ellos con posterioridad a la destinación. Es dicho acto de "enajenación” el que permite cumplir con el requisito de la "ajenidad" de los predios consagrado en los artículos 820 c.c.ch. y 879 c.c.col.; y es en razón de ese cumplimiento y a partir de ese momento que la correspondiente servidumbre resulta constituida, produciendo los efectos tal.

Pues bien, es sabido que el concepto de "enajenación” en nuestro sistema jurídico se entiende en un sentido amplio o en un sentido restringido, dependiendo del texto de la norma que aluda al mismo y de su contexto ${ }^{24}$. En el primer sentido se comprenden tanto los actos de disposición entre vivos que importan una transferencia del derecho respectivo por el sujeto titular a otro, como los actos que significan la constitución de un derecho real que lo limita en favor de un tercero. En el segundo sentido se comprenden solo los actos de transferencia.

Para la aplicación de los artículos 88 I c.c.ch. y 938 c.c.col., la tendencia fue inicialmente considerar el término ("enajena”) en un sentido restringido, considerándose que se refería exclusivamente a las transferencias inter vivos de derechos, precedidas estas desde luego por un título traslaticio del dominio oneroso ( $v$. $g r$., compraventa, permuta, aporte en sociedad, dación en pago, etc.) o gratuito (p. ej., donación $)^{25}$. En otras palabras, en las citadas disposiciones, "enajenación" se interpretaba como sinónimo de "tradición".

Empero, la doctrina comparada ha destacado que lo relevante en el mecanismo constitutivo de la DPF no es en realidad la causa del cambio de propiedad

24 Vodanovic Haklicka, A., Tratado de los derechos reales, versiones de clases escritas de los profesores Arturo Alessandri y Manuel Somarriva, t. I, Santiago, Jurídicas de Santiago, 20 i 67 , n. ${ }^{\circ} 69,56$; Velásquez Jaramillo, L. G., Bienes, Bogotá, Temis, $2014^{\text {I3 }}$, 4I I ; Arévalo Guerrero, I. H., Los bienes, Constitucionalización del derecho civil, Bogotá, Universidad Externado de Colombia, 20 I2, 2 I 2 y 2 I 3.

25 Claro Solar, en Explicaciones, cit., De los bienes, vol. Iv, t. 9, n. ${ }^{\circ}$ I640, 288, habla incluso de "venta”, restringiendo el título de enajenación a un solo acto jurídico. 
de uno de los predios, sino la circunstancia de que efectivamente dicho cambio se produjo, o sea que ambos predios son "de distinto dueño" ${ }^{26}$. A partir de ello, tanto los autores como los tribunales extranjeros han reconocido que "enajenación", "disposición" u otro cualquiera de los términos análogos utilizados por los respectivos códigos civiles en materia de DPF debe interpretarse en el más amplio sentido ${ }^{27}$, comprendiendo otros modos de adquirir distintos a la tradición así como otras causas diferentes a los títulos traslaticios ${ }^{28}$. La regla ha sido igualmente reconocida en Chile ${ }^{29}$.

Así, y aunque no tenga lugar técnicamente un acto de enajenación, se admite sin problemas por la doctrina comparada que la transmisión mortis causa a título singular de la propiedad de uno de los predios se encuentra comprendida en el concepto $^{30}$, lo que ha sido aceptado en nuestro sistema ${ }^{3}$. El caso corresponde al legado de uno de los predios, en que el testamento cumple la función de título gratuito que fundamenta la adquisición de uno de los predios por parte del legatario, mientras que la sucesión por causa de muerte hace las veces de modo por el cual aquel adquiere efectivamente el dominio.

Lo mismo ha ocurrido con aquellos casos en que concurre un título que modifica la propiedad de uno de los predios, pero no la voluntad del dueño. Las hipótesis más insignes al respecto son las de las ventas forzadas en pública subasta y las expropiaciones ${ }^{32}$. La objeción en su admisibilidad podría estar en

26 Véase una síntesis de las posiciones y de la tendencia mayoritaria en Cuadrado Pérez, C., Constitución de servidumbre por signo aparente, Cuadernos de Derecho Registral, Madrid, 2007, I 26 a I39; Manresa y Navarro, J. M., Comentarios al código civil español, t. IV, Madrid, Reus, I9727, 778 y 779; Scaevola, Q. M., Código civil. Comentado y concordado extensamente y totalmente revisado y puesto al dia, Madrid, Reus, I9475, 382 a 386 y 439.

27 Ello incluso plasmado en códigos. Así, el artículo 397.3 de la Compilación del Derecho Civil Foral de Navarra dispone: "Asimismo se considerarán como servidumbre los servicios establecidos con signo aparente entre fincas de un mismo propietario, cuando se separe la propiedad de ambas por actos inter vivos o de última voluntad de aquél, si al tiempo de la separación subsiste el signo y si el título de disposición no excluye expresamente la servidumbre”.

28 Palabras más claras en la materia que las de Guilarte son difíciles de encontrar: "el término enajenación ha de interpretarse en un sentido amplio que, en principio, comprende todas las modalidades de transmisión total del dominio". Guilarte Gutiérrez, V., La constitución voluntaria de servidumbres en el derecho español, Madrid, Montecorvo, I984, p. 448. En el mismo sentido, Albaladejo, Derecho civil, cit., i43; Clemente Meoro, M., Derechos reales y derecho inmobiliario registral, Tirant lo Blanch, 200 I², 356; Ya se habían pronunciado en el mismo sentido en Italia Grosso, G. y Deiana, G., Le servitù prediali, t. i, Torino, utet, I955², 595 y 596.

29 En este sentido, expresamente señala que el requisito es "que se produzca la diferenciación del dominio de los fundos o partes de un fundo, cualquiera sea la causa", Vodanovic, Tratado de los derechos reales, cit., t. II, n. ${ }^{\circ}$ I I 6 I, p. 23 I.

30 Rebolledo, Tratado de servidumbres, cit., t. I, 293 a 295; Díaz, Servidumbres, serventías y relaciones de vecindad, cit., 254.

3 I San Martín Devoto, D., Las servidumbres, Santiago, Conosur, I 998, I 5 I.

32 En Chile, Varas Videla, E., De las servidumbres, tesis de grado para optar al título de licenciado, Universidad de Chile, Santiago, I92 5, 395; SAN MARTín, Las servidumbres, cit., I 5 I; Vodanovic, Tratado de los derechos reales, cit., t. II, n. ${ }^{\circ}$ I I6 I, 23 I. En Italia, Biondi, B., Las servidumbres, trad. 
que no hay acuerdo voluntario en la constitución de la servidumbre a partir de una destinación anterior del dueño (si se siguiera la teoría tradicional voluntarista acerca de la naturaleza jurídica de la DPF). De hecho, la DPF se caracteriza por producir el efecto constitutivo siempre que no haya expresión de voluntad contraria en el título de la enajenación. Sin embargo, modernamente se ha rechazado el carácter voluntario de esta forma de constituir servidumbres, pues lo definitorio en este modo es la diferenciación de propiedades sobre los predios, no el acuerdo de voluntades ${ }^{33}$.

Lo dicho respecto a las expropiaciones tiene lugar siempre que no exista una disposición legal en contrario. Así por ejemplo, en Francia, la sola dictación del decreto de expropiación extingue todos los derechos reales o personales existentes sobre los inmuebles expropiados 34 . Ocurre algo similar en Chile, pues, de acuerdo al artículo 20 de la ley de expropiaciones ${ }^{35}$, con el pago de la indemnización correspondiente queda radicado el dominio del bien expropiado en el patrimonio del expropiante, extinguiéndose por el ministerio de la ley todo derecho real sobre el predio expropiado que "lo afecte o limite". De modo que debe entenderse que no nacerá la servidumbre por DPF si el predio expropiado era el inmueble que tenía la calidad de predio sirviente. En cambio, sí nacerá la servidumbre si el expropiado era el predio dominante, pues en este caso la servidumbre no afecta ni limita el bien raíz sino que, por el contrario, favorece o beneficia al inmueble que se expropia ${ }^{36}$. Por tanto, la postura de los autores que en Chile han sostenido que la expropiación también constituye enajenación

de la 2. ${ }^{\text {a }}$ ed. por J. M. González Porras, Granada, Comares, 2002, n. ${ }^{\circ}$ I 58, 675; Spano, G. y Caruso, S., "Le servitù prediali”, en Cendon, P. (ed.), Trattati, Milano, Giuffrè, 20 I3, 533. En España, Túr Faúndez, M., "Mediante signo aparente (o por destinación del padre de familia)", en Cerdeira, G. (ed.), Tratado de servidumbres, Madrid, La Ley, 20 i 5, p. 587 . En Francia, Terré, F. y Simler, P., Droit civil: Les biens, 9. ${ }^{\mathrm{a}}$ ed., Paris, Dalloz, 20 I4, n. ${ }^{\circ} 90 \mathrm{I}, 797$. Beauvarlet, P., Les servitudes, Paris, Defrénois, 2013, n. $^{\circ} 25$ I, p. 196.

33 Ver sobre esta dificultad, con cita de doctrina española favorable a la constitución de la servidumbre, Rebolledo, Tratado de servidumbres, cit., t. I, 294, nota 98; y síntesis de Cuadrado, Constitución de servidumbre, cit., I 3 I a I35. Particularmente, Grosso y Deiana, Le servitù prediali, cit., 595, sostuvieron acertadamente que la referencia del legislador a la no existencia de voluntad contraria en el título de enajenación no tiene por objeto restringir la causa de la separación dominical solo a títulos voluntarios, sino aclarar que si el título es de esta naturaleza, y solo en tal caso, puede expresarse en él la no continuación del servicio como servidumbre.

34 Art. L222-2 del Code de l'expropriation pour cause d'utilité publique: "L'ordonnance d'expropriation éteint, par elle-même et à sa date, tous droits réels ou personnels existant sur les immeubles expropriés". Lo anterior conforme texto fijado por Ordonnance n. ${ }^{\circ} 20 \mathrm{I} 4-\mathrm{I} 345$ du 6 novembre 2014 (anteriormente, la disposición se encontraba en el artículor 2-2 del mismo código).

35 Decreto Ley 2 I 86 de I978, Ley orgánica de procedimiento de expropiaciones.

36 Expresamente admite esta solución como de aplicación general Clemente, Derechos reales, cit., p. 356, quien sostiene que en caso de expropiación forzosa la Administración ha de quedar libre de toda carga o gravamen, por lo que el expropiado no puede mantenerse como dueño del predio dominante, pero sí como dueño del predio sirviente, si no hizo desaparecer el signo aparente antes de la expropiación. 
para los efectos de la aplicación de la DPF debe entenderse en este sentido. De lo contrario, sería una opinión sin sustento en la ley. El mismo efecto que en Chile se alcanzaría en Colombia por vía de la aplicación del artículo 70 n. ${ }^{\circ}$ I de la Ley 388 de 1997 .

Adicionalmente a lo ya expresado, se debe señalar que incluso no es necesario que exista título alguno para que se produzca la separación en la propiedad de los predios. Una de las discusiones tradicionales en este sentido fue si era admisible o no la usucapión de uno de los predios como causa de dicha separación y, por tanto, como “enajenación”. La cuestión se encuentra ya zanjada, pues la mayoría de los doctrinarios nacionales y extranjeros se ha pronunciado positivamente por la admisión 37 . Adherimos a esta postura, pues se trata de un modo de adquirir que permite cumplir efectivamente con el requisito de que ambos predios sean "de distinto dueño".

Por último, caso particular lo constituye la sucesión por causa de muerte a título universal, pues la transmisión abintestato a dos o más herederos de los predios entre los cuales se estableció el servicio por el de cujus, y a diferencia de otros ordenamientos, se encuentra regulada expresamente en nuestros códigos civiles. En efecto, los artículos 88 I c.c.ch. y 938 c.c.col., además de la enajenación de uno de los predios, contemplan la situación en que "pasan a ser de diversos dueños por partición".

Ciertamente la partición no es ni un título que fundamente una enajenación ni, menos, un acto de enajenación. Por el contrario, "la adjudicación es totalmente inversa a la enajenación; son términos radicalmente opuestos en derecho" $3^{8}$. Mediante de la partición no se adquiere predio alguno, pues se trata solo de un título declarativo de una adquisición en favor del adjudicatario que se produjo en el momento de deferirse la herencia del causante. Lo anterior en razón de que la partición tiene efecto retroactivo, según establecen los artículos I 344 c.c.ch. y I 40 I c.c.col. Desde esta perspectiva, sería correcta la determinación del legislador de tratar la partición en forma independiente de la enajenación.

Ahora bien, en el tiempo intermedio entre la muerte del causante y el acto de división se podría entender formada una copropiedad entre los herederos respecto de cada uno de los predios, lo que implicaría que ninguno de los comuneros tenga la titularidad completa sobre los respectivos predios entre los cuales el causante estableció el servicio. Ello podría llevar a pensar que es la muerte del causante (propietario único) la causa que produce la separación de la propiedad

37 En Chile, VARAs, De las servidumbres, cit., 395; SAN MARTín, Las servidumbres, cit., I 5 I; Vodanovic, Tratado de los derechos reales, cit., t. II, n. ${ }^{\circ}$ i I 6I, p. 23 I. En derecho comparado, Biondi, Las servidumbres, cit., n. ${ }^{\circ}$ I 58, p. 675; Spano y Caruso, Le servitù prediali, cit., p. 5 I 3; Tur, Mediante signo aparente, cit., 587; Bonet CoRrea, J., La constitución de las servidumbres por signo aparente, Madrid, Consejo Superior de Investigaciones Científicas, I970, 97 y 98.

38 Somarriva Undurraga, M., Derecho sucesorio, iI, versión de René Abeliuk, Santiago, Jurídica de Chile, $2016^{8}$, n. ${ }^{\circ} 806,638$. 
(varios herederos copropietarios). Sin embargo, la mayoría de la doctrina y la jurisprudencia comparadas, aun cuando no contemplan una disposición como los artículos 88 I c.c.ch. y 938 c.c.col., llegan a la conclusión de que la separación de propiedades tiene lugar con la partición39. Esta postura se explica principalmente por la incomunicabilidad de la cuota parte sobre la universalidad hereditaria a los bienes individuales que la integran.

En nuestro sistema jurídico, en cambio, no existe discusión al respecto, no solo por las referidas normas expresas, sino porque además se contempla el derecho real de herencia. Este derecho reafirma la circunstancia de que no procede la comunicabilidad de las cuotas hereditarias sobre los bienes singulares que componen la masa hereditaria $4^{\circ}$, pues los herederos son únicamente titulares de este derecho real, cuyo objeto es precisamente dicha masa. Por lo mismo, y en lo que nos interesa, en la abstracción de nuestro legislador no podría haber copropiedad respecto de los predios ni, en consecuencia, separación de dominio. Este solo tiene lugar después de la partición, acto a partir del cual se entiende que nunca hubo derecho real de herencia ni otros herederos con eventuales derechos sobre los predios respectivos, todo ello en razón de su efecto retroactivo. Adicionalmente, es la partición el acto que permite al adjudicatario del predio sirviente expresar su voluntad en contrario al nacimiento de la servidumbre.

\section{B. Cambios en los derechos sobre los predios a los cuales se debe extender el concepto de "enajenación"}

La sola consideración de que es el cambio de dominio sobre uno de los predios lo que activa la DPF, con independencia de su causa, constituye por sí misma una interpretación extensiva del concepto de "enajenación”. Sin embargo, para superar el problema de la "oportunidad" que enfrentamos, cabe examinar la posibilidad de una ulterior extensión. Sobre el particular se ha debatido particularmente respecto de las situaciones sobrevenidas de copropiedad, de constitución de derechos reales, o del otorgamiento de derechos personales sobre uno de los predios entre los cuales se estableció el servicio.

En cuanto a la copropiedad sobreviniente, recuérdese que hasta ahora el análisis siempre ha tenido como base la transferencia o transmisión íntegra del dominio de uno de los predios. Ahora cabe preguntarse si la transferencia o transmisión de solo una cuota de la propiedad sobre uno o ambos predios a un

39 Así en España, Bonet, La constitución de las servidumbres por signo aparente, cit., 98 a Io I; CuADRADo, Constitución de servidumbre, cit., I35 a I39; Tur, Mediante signo aparente, cit., p. 587; Rebolledo, Tratado de servidumbres, cit., t. i, 295. En Italia, Spano y Caruso, Le servitù prediali, cit., 543 y 550. En Francia, Terré y Simler, Droit Civil, n. ${ }^{\circ} 90$ i, 797.

40 Sobre esta incomunicabilidad en Chile, Somarriva Undurraga, M., Indivisión y partición, Santiago, Jurídica de Chile, $2002^{5}$, reimp. 20 i6, n. ${ }^{\text {os }}$ I 6 y I 7, 40 y 41. En contra, Silva SEgura, E., Acciones, actos y contratos sobre cuota, Santiago, Jurídica de Chile, I $985^{2}$, n. ${ }^{\circ} 73$, I 2 I y I 22. 
tercero genera el efecto de constituir la servidumbre por DPF. En esta situación debe tenerse presente que el propietario primitivo mantiene una cuota del dominio sobre los predios. Luego, podría entenderse que no ha tenido lugar la "enajenación" de uno de los predios en sentido estricto.

Mas, no obstante la reserva de parte del dominio del propietario original de los predios, lo cierto es que su ius dominii ya no es ni total ni absoluto, pues ha perdido su libre ejercicio; o si se prefiere, dicho poder se ha reducido ${ }^{4 \mathrm{I}}$. La concurrencia de una alícuota del dominio, por mínima que sea la fracción de dominio adquirida por un tercero sobre uno de los predios, llevaría necesariamente a que el servicio deba subsistir como servidumbre, pues la pérdida del control total de los predios por el propietario original hace que tenga sentido la existencia del servicio como derecho real, sobre todo teniendo en cuenta la indivisibilidad de las servidumbres.

Desde el derecho romano ${ }^{42}$, y en virtud de la citada indivisibilidad, se ha reconocido que las servidumbres existentes no se extinguen por consolidación cuando el dueño del predio dominante o sirviente adquiere solo una cuota del predio sirviente o dominante respectivamente 43 . En este sentido, los mismos artículos 885 n. ${ }^{\circ} 3$ c.c.ch. y 942 n. ${ }^{\circ} 3$ c.c.col. exigen una "reunión perfecta", además de irrevocable, "de ambos predios en manos de un mismo dueño". Si solo se ha adquirido una cuota del dominio del otro predio, la reunión es aún imperfecta, razón por la cual la doctrina unánimemente ha estado de acuerdo en que la copropiedad no extingue la servidumbre 44 . De manera que, si frente a una copropiedad sobreviniente no hay extinción, frente a una copropiedad sobreviniente necesariamente debe haber constitución. La extinción y la constitución no son sino dos caras de la misma moneda, debiendo operar idénticamente en ambas situaciones el principio nemini res sua servit iure servitutis. Así las cosas, la doctrina moderna se ha ido uniformando en aceptar sin mayores inconvenientes que la concurrencia de una copropiedad sobre uno de los predios o de ambos es un caso que se encuentra comprendido en el concepto de enajenación. Esta posición se ha visto por ejemplo plasmada en los nuevos códigos civiles de las comunidades autónomas españolas 45 .

P. ej., D. 8.r.8. I y D. 8.2.30.r. En D. 8.3.27, Juliano planteaba sí como excepción el caso en que los codueños de un predio dominante adquirían, también de modo común, el predio sirviente, pues afirmaba que comenzaba a ser igual el derecho de los dueños en uno y otro fundo, lo que redundaba en la extinción de la servidumbre.

43 García Alguacil, Consolidación, cit., i I6 a I 2 I

44 En Chile, Vodanovic, Tratado de los derechos reales, cit., t. II, n. ${ }^{\circ}$ I I 70, p. 238 ; San Martín, Las servidumbres, cit., p. 268. En Colombia, Velásquez Jaramillo, Bienes, cit., p. 429.

45 El Código Foral de Aragón en su artículo 564 n. 2 señala precisamente respecto de las servidumbres sobre finca propia que "Si los titulares de la finca dominante y de la sirviente coinciden parcialmente, la servidumbre producirá efectos desde el momento de su constitución”. El artículo 93 de la ley de Galicia señala que "La servidumbre de paso, cualquiera que sea su forma de 
A continuación, si por un acto voluntario del propietario, o bien contra su voluntad (por imposición de la ley o sentencia de los tribunales), tiene lugar la constitución de otros derechos reales diversos al dominio sobre uno de los predios entre los cuales se estableció el servicio, ¿puede tal situación entenderse como "enajenación” para los efectos que tratamos? En principio, nos parece que la respuesta podría haber sido fácil en nuestros países, pues bastaría entender que la enajenación, en los artículos 88 I c.c.ch. y 938 c.c.col., fue tomada en su acepción amplia, conforme a la cual quedan comprendidos los actos de constitución de derechos reales. Sin embargo, no hay en nuestro sistema pronunciamientos en este sentido.

La situación es distinta en la doctrina extranjera, donde la cuestión ha sido planteada y debatida. Así, en Italia, Biondi acepta la posibilidad en comento pero con base en un argumento distinto: si a los titulares de derechos reales les está permitido constituir servidumbres, se debe admitir que la separación de predios no solo puede tener lugar a título de dominio, sino que también puede producirse por la constitución de un derecho real sobre uno de los predios ${ }^{4}$. Ello desde luego sin perjuicio de que la vigencia de la servidumbre será igual a la duración del derecho real. Entonces, y de acuerdo a esta postura, la servidumbre nace no obstante el propietario de los predios no cambia.

Aunque en Chile y Colombia se admite la facultad del usufructuario de constituir servidumbres, y la regla de la vigencia de la servidumbre por todo el tiempo que dure el usufructo tiene base legal (arts. 794 c.c.ch. y 853 c.c.col.), el problema de la explicación de Biondi es que no proporciona una razón sustantiva del porqué es admisible jurídicamente una servidumbre entre predios de un mismo propietario.

En España, Cuadrado parece dar solución a esta dificultad, intentando una respuesta a partir del principio nemini res sua servit. En su concepto, "la circunstancia decisiva para impedir el establecimiento o mantenimiento de una servidumbre de propietario no es la titularidad dominical común de ambos predios, sino la posibilidad de ejercitar 'iure dominii' las facultades que a ese sujeto confiere el derecho real de servidumbre" 47 . Y justamente, Albaladejo rechaza que se le niegue al propietario una servidumbre sobre el predio entregado en usufructo, pues el nudo propietario no tiene las facultades comprendidas en la servidumbre aunque sea propietario de este último. Por tanto, "no parece absurdo", dice, que a estos nuevos poderes de que carece se les apliquen las reglas de las servidum-

constitución, se extinguirá por: I. $^{\circ}$ Reunirse en una misma persona la propiedad de los predios dominante y sirviente. Cuando lo que se adquiere es una parte indivisa, la servidumbre no se considerará extinguida".

46 Biond, Las servidumbres, cit., n. ${ }^{\circ} 49,2$ I 7 ; n. ${ }^{\circ}$ I $58,676$.

47 Cuadrado, La servidumbre de propietario, cit., 87. 
bres $^{4}{ }^{8}$. Nos parece que esta es la postura correcta así como su fundamento, el cual profundizaremos en el acápite siguiente.

Dicho lo anterior, y dado que donde existe la misma razón debe existir la misma disposición, no puede sino entenderse que la doctrina expresada por los autores españoles rige para la constitución de cualquier derecho real; esto es, tanto para los de uso y goce (p. ej., usufructo, uso o habitación) como para los de garantía constituidos sobre bienes raíces.

Entre estos últimos se destaca, por su relevancia, el de hipoteca. Así, conforme a la citada doctrina, si el propietario de dos predios entre los cuales había establecido un servicio constituye un derecho real de hipoteca sobre uno de ellos en favor de un tercero, o dicho derecho es impuesto por la ley49, el servicio adquiere jurídicamente el carácter de servidumbre por DPF. Obviamente, la servidumbre así constituida tendría igual vigencia que la hipoteca, por lo que, extinguida esta, se extinguiría también la servidumbre. Esto si la hipoteca no se hace efectiva, pues, en caso de ejecución y venta en pública subasta, la servidumbre mantendrá su vigencia, afectando pasiva o activamente al adquirente. En todo caso, si se extingue la hipoteca, el propietario puede mantener el servicio entre los predios.

La transformación del servicio en virtud de la constitución de un derecho real sobre uno de los predios importa en definitiva una ampliación del concepto de enajenación, lo que ha motivado su rechazo por parte de quienes insisten en una interpretación restringida del término y reducida solo a la separación dominical. El motivo fundamental para esto ha sido simplemente el tenor literal de la ley $5^{\circ}$. Algunos de ellos plantean que debiera respetarse el servicio dispuesto por el propietario como un derecho personal y no como gravamen real. El problema es que no se advierte en este último caso el título o causa que tendría este derecho "al servicio", cuyo origen es una destinación de hecho ${ }^{51}$.

En una suerte de posición intermedia están los autores que admiten el nacimiento de la servidumbre solo cuando se constituyen "ciertos" derechos reales;

48 Albaladejo, Derecho civil, cit., io4.

49 P. ej., en Chile, el artículo 662 del código de procedimiento civil da por constituida hipoteca sobre los bienes raíces adjudicados a uno de los comuneros, para garantizar el pago de los alcances. El artículo 22 I de le Ley 20.720 da por constituida hipoteca por el solo ministerio de la ley sobre los bienes raíces que integran la unidad económica, cuando se proceda a la venta con tal carácter de los bienes de quien se encuentra sujeto a un procedimiento concursal de liquidación.

50 Rebolledo, Tratado de servidumbres, cit., t. I, 293; lo sigue Tur, Mediante signo aparente, cit., 586 ; Venezian, G., Usufructo, uso o habitación, R. Atard (trad.), t. II, Madrid, Revista de Derecho Privado, I 928, n. ${ }^{\circ} 242$, I6r a I64.

5 I En esta postura podría enmarcarse la opinión dada por Rebolledo, Tratado de servidumbres, cit., t. I, 293, y de Venezian (ver nota precedente), quienes plantean que debiera respetarse el servicio pero como derecho personal y no como gravamen real, sin indicar el fundamento para ello. En la misma línea Díaz, Servidumbres, cit., 308, recurriendo a la obligación del arrendador de mantener al arrendatario en el goce pacífico de lo arrendado. 
es decir, la ampliación del concepto de enajenación sería parcial. En este sentido, los italianos Grosso y Deiana están de acuerdo con que el servicio entre dos predios dispuesto por su propietario se transforme en servidumbre por DPF solo cuando se constituya un derecho real de enfiteusis sobre uno de ellos. Y si bien esta posición se funda en el mismo argumento dado por Biondi ${ }^{2}$, rechazan por el contrario que al mismo resultado se pueda llegar mediante la constitución de un usufructo (u otro derecho de goce análogo, como el uso y la habitación), pues esta no habría sido la voluntad del legislador ni sería avalado por los antecedentes históricos ${ }^{53}$.

La idea de los referidos autores es retomada por Guilarte, en cuanto postula la tesis de que la servidumbre nace si los derechos reales constituidos son los de enfiteusis y de superficie. La razón, sin embargo, sería que al enfiteuta y al superficiario los considera propietarios, con lo cual en realidad acepta esta posibilidad porque habría separación en la propiedad. Desde esta perspectiva, el concepto de enajenación sigue entendiéndose en sentido restringido ${ }^{54}$. De hecho, Guilarte excluye de esta noción al usufructo porque en su concepto el usufructuario no podría, por el contrario, ser calificado como propietario del fundo55. Esta diferencia no resulta menor para Chile y Colombia, pues, no habiendo sido regulados en sus códigos civiles los derechos reales de enfiteusis y de superficie, el análisis más relevante en la materia, y que puede dar sustento dogmático a la ampliación de enajenación, es precisamente el que se realice sobre el usufructo.

Finalmente, la situación más compleja dice relación con el otorgamiento a terceros de derechos personales respecto de uno de los predios, la mayoría de las veces de uso, asociado en ocasiones al goce. El ejemplo más habitual es el de los derechos derivados del contrato de arrendamiento. Si estamos a la dogmática tradicional, debiera responderse negativamente a la posibilidad de considerar la concesión de esta clase de derechos comprendida en el concepto de enajenación. Esto porque los títulos constitutivos de fuente de créditos solo entregan la mera

52 Grosso y Deiana, Le servitù prediali, cit., 598, nota 20.

53 Ibíd., 599. La postura de estos autores resulta bien curiosa. Por una parte, declaran en términos generales que es posible la existencia de un servidumbre entre predios de una misma persona. En coherencia con esta idea, aceptan el surgimiento de la servidumbre si, sobre uno de los fundos, se constituye una enfiteusis en favor de un tercero. Esto último, pese a que no se ha producido separación alguna del dominio y a pesar del lenguaje del artículo io62 c.c.it. (“cessarono di appartenere allo stesso proprietario"). Sin embargo, rechazan que lo mismo ocurra cuando se constituye un usufructo, en virtud del tenor literal del citado artículo. Le servitù prediali, cit., 598 y 599 .

54 Cuadrado, Constitución de servidumbre, cit., I47 a I74, examina sintéticamente la postura de Guilarte, complementándola con las teorías acerca de la naturaleza jurídica de la enfiteusis y del derecho de superficie. Desde luego, si al enfiteuta o al superficiario se le atribuye el carácter de propietario, es evidente que la constitución de tales derechos debe incluirse en la enajenación.

Guilarte, La constitución, cit., 457 y $45^{8}$. 
tenencia de los bienes que tienen por objeto ${ }^{5}$. El acreedor no adquiriría derecho alguno sobre la cosa, sino solo respecto de la persona del deudor. Desde esta perspectiva, ningún carácter real "ajeno" concurriría sobre la cosa.

Sin embargo, los resultados a los que se arriba adoptando esta concepción tradicional no son convincentes, además de terminar provocando buena parte de los problemas descritos en el acápite I. Pensemos en el caso del propietario de dos predios que establece entre ellos un servicio mediante escritura pública inscrita en el registro de propiedad, incluso con plano que lo ilustra. Posteriormente, arrienda uno de los predios y nada se dice sobre dicho servicio en el contrato respectivo. Si el arrendatario tomó en arriendo el predio gravado con el servicio, ¿puede oponerse a que el propietario-arrendador siga utilizando el servicio establecido sobre el predio arrendado? Por el contrario, si el arrendatario tomó en arriendo el predio en cuyo favor fue establecido el servicio, ¿puede exigir al propietario-arrendador que se le permita continuar beneficiándose de tal servicio sobre el otro predio del arrendador y en utilidad del que arrienda? En razón de no encontrarnos ante una enajenación, según la tesis tradicional, las respuestas a las dos preguntas formuladas serían necesariamente negativas.

De lo anterior se desprendería que, en lo concerniente a la primera pregunta, habría que entender que el propietario-arrendador cedió el uso y goce de uno de los predios (que sería el sirviente), asumiendo la obligación contractual de no perturbar en este uso y goce al arrendatario, sin tener la facultad de oponer el servicio en calidad de servidumbre; o sea, como un derecho real en su favor que primaría por sobre la referida obligación de no disturbar al arrendatario. Asimismo, en lo concerniente a la segunda pregunta, habría que entender que el propietario-arrendador solo cedió al arrendatario el uso y goce sobre uno de sus predios (que sería el dominante), sin adquirir este la facultad adicional de oponer al arrendador el servicio que existía en carácter de servidumbre, limitando el uso y goce que el dominio le concede como propietario.

No faltará el que piense que estos resultados se deben a la propia negligencia de las partes, que no incluyeron en el contrato de arrendamiento una cláusula referida al servicio, sea que favoreciera al arrendador o al arrendatario. Mas, se trata de una posición simplista frente al caso descrito, sobre todo si el servicio figuraba en los registros inmobiliarios, pues habría que entender que ambas partes contrataron a sabiendas de la destinación unilateral del dueño. Incluso, siguiendo con las respuestas simples, podría considerarse que dicha declaración formaba parte de las condiciones de contratación, pues la destinación era una oferta que fue aceptada por el arrendatario.

56 En este sentido Grosso y Deiana, Le servitù prediali, cit., 6oo, sin perjuicio de que advierten que surgiría el problema entre arrendador y arrendatario acerca de si tienen o no la obligación de no modificar la situación de servicio. 
En buena medida, los efectos negativos descritos a propósito de la concesión de derechos personales y la búsqueda de soluciones más sustanciales (y no simplistas) llevaron a la doctrina y al legislador a aceptar la excepción al principio nemini res sua servit iure servitutis que importan las denominadas "servidumbres de propietario". Y claro, la admisión de la constitución unilateral de servidumbres cambia todo, pues si se reconoce la existencia de estas, significa que estamos en presencia de un derecho real en favor del predio dominante, o de un gravamen impuesto al predio sirviente, que puede ser opuesto como servidumbre por el arrendador al arrendatario o viceversa, dependiendo de cuál de los dos predios sea el arrendado57. Es decir, un absurdo (que no nazca la servidumbre) se soluciona con otro absurdo: admitir que los propietarios requieren de derechos reales de servidumbre adicionales a su dominio, a fin de que gocen de facultades que este no es capaz de otorgarles. Todo ello sin perjuicio de que la solución exige un cambio legal.

Hoy, sin embargo, ya es posible encontrar opiniones que admiten como enajenación el otorgamiento de derechos personales a un tercero, y que, por ende, están de acuerdo con el nacimiento de servidumbres establecidas con anterioridad como servicios entre los predios por su dueño; es decir, sin necesidad de recurrir a la servidumbre de propietario. En este sentido, Cuadrado hace aplicable al arrendamiento el mismo argumento tenido en consideración para el caso de que se constituyesen derechos reales sobre uno de los $\operatorname{predios}^{5}$ : la celebración del contrato de arrendamiento comporta para el propietario la imposibilidad de ejercer respecto del predio arrendado iure dominii las facultades que le otorgaría una servidumbre pues (citando incluso a Guilarte) las fincas ya no se hallarían en la misma situación para su propietario. Por lo mismo, no supondría un absurdo concederle en este caso un derecho de servidumbre a fin de recobrar los poderes que esta le concedería 59 .

\section{Relectura ampliada del concepto de "enajenación" en materia de destinación del padre de familia}

Frente a las ampliaciones ya aceptadas, y las posibles ampliaciones aún discutidas en doctrina, estamos convencidos por nuestra parte de que "enajenación”, en

57 Debe recordarse a este respecto que las servidumbres son inseparables del predio al cual activa o pasivamente pertenecen de acuerdo a los artículos 825 c.c.ch. y 883 c.c.col. Por tanto, la cosa objeto del arriendo incluye el derecho real o gravamen según corresponda.

$5^{8}$ Cuadrado, La servidumbre de propietario, cit., 89 y i 98 . Albaladejo, Derecho civil, cit., io4, si bien no se pronuncia expresamente, señala que la afirmación de que el dueño usa y disfruta de su cosa por el derecho de propiedad no solo se puede desmentir desde el punto de vista de los derechos reales sino también desde el punto de vista del derecho de las obligaciones, con lo cual el problema es el mismo y la solución, entonces, debiera ser idéntica. 
los artículos 88 I c.c.ch. y 938 c.c.col., para efectos de una aplicación correcta y efectiva de la DPF, debe ser interpretada en los términos más amplios posibles. Ello, en primer lugar, conforme a lo que real y técnicamente manda el verdadero sentido y alcance del principio nemini res sua servit iure servitutis; en segundo lugar, de acuerdo al criterio que debe aplicarse para determinar el nacimiento del derecho real de servidumbre a través de DPF; en tercer lugar, según la noción vigente en el sistema jurídico chileno y colombiano de propiedad, la que tiene por objeto tanto cosas corporales como incorporales; y, en cuarto lugar, en razón de la ampliación moderna del concepto de predio, el cual incluye hoy cosas incorporales. A continuación pasamos a revisar estas razones.

\section{A. La ampliación del concepto de enajenación tiene por fundamento el principio nemini res sua servit iure servitutis}

Es este principio el que debe gobernar finalmente todas y cada una de las interpretaciones que se hagan de las disposiciones legales que en él se basan directa o indirectamente. Desde esta perspectiva, no interesa si el resultado es un sentido y alcance restrictivo o bien extensivo de la norma jurídica. Lo relevante es que dicho resultado constituya una fiel aplicación del principio nemini res sua servit iure servitutis.

En esta línea, con formidable agudeza y claridad respecto de la cuestión que tratamos, Biondi planteó que el principio debe ser aplicado teniendo en cuenta su fundamento, de modo que para dar solución a los problemas prácticos que se presentan "no es oportuno negar en general valor al principio o pedir su supresión, cuando se puede llegar al mismo resultado mediante una razonable interpretación"6o. En este contexto, el insigne tratadista propuso como regla que las servidumbres pueden surgir o no extinguirse entre fundos de un mismo dueño, cuando ello es prácticamente útil y jurídicamente posible ${ }^{6 \mathrm{I}}$.

Asimismo Guilarte adopta una posición que, si bien puede estimarse contradictoria, no hace más que ratificar cuál es el verdadero problema y cuál es la verdadera solución. El autor español está de acuerdo con que la constitución de derechos reales sobre uno de los predios del mismo dueño dé vida a la servidumbre (y por ende se considere enajenación), considerando que "sería más acertada la tesis de Biondi”. Sin embargo, rechaza a continuación esta conclusión únicamente por razones formales, pues la letra del artículo 54I c.c.es. dice: "al tiempo de separarse la propiedad de las dos fincas". Entonces, expresa que si bien es más coherente seguir la tesis del autor italiano, "la letra de la ley nos lo

60 Biondi, Las servidumbres, cit., n. ${ }^{\circ} 49,2$ I 5 .

6I Biondi, Las servidumbres, cit., n. ${ }^{\circ}$ 49, 2 I 7 y 2 I 8 . Comparte la opinión Jordano, Prehorizontalidad, cit., I65; García Alguacil, Consolidación, cit., ro6. 
impide"62. Incluso, Guilarte admite el argumento de Cuadrado, señalando que deben buscarse válvulas de escape (a la letra de la ley), como es la aceptación de que el otorgamiento de los derechos reales de enfiteusis y de superficie son un acto de enajenación, bajo la idea de que estos derechos otorgan la propiedad sobre el predio respectivo ${ }^{63}$.

El problema, como se aprecia entonces, está simplemente en las interpretaciones exegéticas tradicionales de las disposiciones que regulan la DPF, las cuales no atienden ni al fundamento de la institución ni a su verdadero sentido y alcance. Por el contrario, dichas interpretaciones han aplicado el principio nemini res sua servit iure servitutis como si fuera una limitación al dominio para el propietario, en vez de aplicarlo como un beneficio para este. Ya hemos hecho ver en un trabajo anterior esta dificultad, así como que la frase nemini res sua servit iure servitutis, si bien literalmente puede traducirse como "la cosa propia no sirve a ninguno por derecho de servidumbre", lo que jurídica y sustancialmente expresa es que "ningún propietario necesita de un derecho de servidumbre para servirse de la cosa propia"64.

Este último es el verdadero y propio sentido del principio. El dueño resulta favorecido y amparado por él, pues el ius dominii le basta para ejercer todos los poderes posibles que el ordenamiento jurídico le reconoce sobre los predios de su propiedad. No necesita por tanto añadir al dominio servidumbres para usar, gozar o disponer de los predios mediante el servicio que uno pude prestar al otro. Y si bien este razonamiento no es desconocido para la doctrina, a tal punto que es explicitado por algunos doctrinarios ${ }^{6}$, al momento de hacer efectivo el correcto entendimiento del principio a los casos prácticos, en vez de hacerlo en términos de beneficio para el propietario, lo hacen en términos de limitación.

Desde luego, la aplicación del principio como limitación al dominio termina siendo muy contradictoria y perjudicial para el dueño. Inicialmente no se le permite constituir servidumbres sobre cosa propia porque como dueño no las necesita (lo que es una ventaja); pero cuando requiere que los servicios que estableció en o entre predios de su propiedad tengan el carácter de derecho real de servidumbre en razón de alguna utilidad o beneficio que como propietario desea obtener frente a terceros, tal posibilidad le es negada, precisamente por ser dueño (lo que constituye un perjuicio). En otras palabras, se concede a los propietarios un beneficio que los perjudica.

Esta evidente contradicción, y sobre todo el menoscabo a los propietarios, se evita reconociendo que el beneficio que el principio les otorga se extiende

62 La constitución, cit., 456 y 457 . Destaca que Guilarte reconoce que la teoría de Biondi es la más adecuada, Cuadrado, Constitución de servidumbre, cit., I47.

63 Guilarte, La constitución, cit., 457 y $45^{8}$.

64 Rosso, Constitución de servidumbres sobre predio propio, cit., I33.

65 Jordano, Prehorizontalidad, cit., I64. 
objetivamente ante cualquier hecho que importe la transmisión o disposición voluntaria o involuntaria de derechos a terceros respecto de los predios (salvo voluntad en contrario por los legitimados legales para expresarla antes de la trasmisión o disposición). Tal reconocimiento se traduce concretamente en concederle al dueño la facultad de oponer los servicios constituidos unilateralmente sobre sus predios a los terceros, hayan estos adquirido sobre uno de los predios una cuota de propiedad, derechos reales o derechos personales. Por el contrario, es precisamente la negación de dicha posibilidad lo que genera en definitiva todos los problemas planteados en el acápite I.

¿Cómo se alcanza dicha oponibilidad? Admitiendo que los servicios, luego de la ocurrencia del hecho transmiticio o de disposición jurídica, han adquirido el carácter de servidumbre; o dicho de otro modo, porque han adquirido el carácter de servidumbre, los servicios resultan oponibles a terceros. Se trata simplemente de dos caras de una misma moneda. Antes del hecho transmiticio o dispositivo no necesitaba el propietario que los servicios establecidos entre los predios fueran servidumbres, mas, después de dicho hecho o disposición jurídica, lo que requiere el propietario es que se les reconozca a los mismos la calidad de servidumbres. El beneficio que significa para el dueño el principio nemini res sua servit iure servitutis exige entonces ambas cosas: el nacimiento de las servidumbres y la oponibilidad que conllevan. Esto sería lo útil y jurídicamente posible en términos de Biondi (y no útil pero jurídicamente imposible, como ocurre con las servidumbres de propietario).

\section{B. Criterio que determina la constitución del derecho real de servidumbre a través de la destinación del padre de familia}

Conforme a lo expresado en precedencia, ¿cuál debiera ser el criterio con base en el cual correspondería decidir si el servicio es o no oponible a terceros a fin de mantener el beneficio que el principio nemini res sua servit iure servitutis dispensa al propietario? La respuesta resulta esencial en la materia, pues proveerá del elemento que permite reconocer que el cambio en la naturaleza de la destinación se ha producido (de servicio de hecho a servidumbre de derecho) y, por sobre todo, la oportunidad en que dicho cambio ocurrió.

$\mathrm{Al}$ respecto, postulamos que dicho criterio es el interés jurídico del tercero, de modo que desde que concurra dicho interés sobre uno de los predios, el propietario tiene el derecho a oponerlo al interesado, pues solo de esa forma el principio lo beneficia. La respuesta contraria, en cambio, lo lesiona irremediablemente. En consecuencia, es a partir del nacimiento de dicho interés que nace la servidumbre, pues es desde ese momento que esta cobra sentido; y al revés, en cuanto falte dicho interés, la existencia de la servidumbre no tendrá ninguna importancia. Mientras no aparezca un interés jurídico de tercero, el ius dominii rige plenamente y puede ser ejercido en forma absoluta (con las limitaciones eviden- 
temente impuestas por la constitución, la ley y el derecho ajeno). Y no es que el derecho de dominio impida el nacimiento de la servidumbre, sino que, como dijimos, la hace innecesaria, pues en eso consiste el beneficio para el propietario ${ }^{66}$.

Nótese que lo antes afirmado es aplicable incluso a la institución de la "servidumbre de propietario", pues el derecho real que pudiera haber nacido en favor y en contra del propio dueño, por un acto jurídico unilateral de este, en realidad no lo necesita hasta que exista un interés jurídico de tercero de por medio. Así lo admiten expresamente los comentaristas de los códigos en que fue acogida la institución o partidarios de ella, quienes afirman que la servidumbre así constituida existe, aunque se encuentra en estado "latente", pues su ejercicio queda diluido en el ejercicio de un derecho de contenido más amplio, como es el de propiedad ${ }^{67}$. Por lo mismo, "la titularidad se disocia del ejercicio, que se producirá con la separación de titularidades o cuando un tercero ostente un derecho no preferente" ${ }^{68}$. Igualmente el propietario, de la misma forma que constituyó la servidumbre, puede dejarla sin efecto unilateral y arbitrariamente cuando quiera. La única limitación que tendrá sin embargo para proceder a su extinción voluntaria será precisamente la presencia de un interés jurídico de tercero sobre uno de los predios. Así lo reconocen expresamente algunos códigos que han acogido la institución en comento ${ }^{69}$. De modo que el dueño no podrá disponer de la servidumbre libremente ante la presencia de dicho interés ${ }^{7 \circ}$.

Lo expresado se debe a que en verdad los efectos del principio nemini res sua servit iure son siempre respecto de terceros. Es precisamente la concurrencia de un interés jurídico de tercero sobre uno de los predios lo que determina el nacimiento del derecho de servidumbre; y su desaparición produce, por el contrario, la extinción de este. Por consiguiente, mientras no exista ese interés de tercero, el propietario puede dejar sin efecto el servicio en cualquier momento y a su solo

66 Se advierte que un esbozo de estas ideas es posible encontrarlo en algunos reconocidos autores, aunque sin profundizar desde la perspectiva que lo hacemos nosotros. Al respecto, Bonet ya decía con razón que "el uso de estos servicios se hace en base a la titularidad dominical de su propietario y el alegar un derecho de servidumbre no tiene sentido, ya que carece de un contradictor, de un interés o una voluntad ajena que se le imponga para que use en esta o en aquella forma”. Bonet, La constitución de las servidumbres por signo aparente, cit., I34. A contrario sensu, es la presencia de un contradictor, de un interés o voluntad ajena lo que le da sentido a la existencia de la servidumbre y, por ende, que el servicio modifique su naturaleza a esta.

67 Del Pozo Carrascosa, P.; Vaquer Aloy, A. y Bosch Capdevila, E., Derecho civil de Cataluña, Derechos reales, Madrid, Marcial Pons, 2010, 275.

68 LLÁCER, La servidumbre sobre finca propia, cit., 277.

69 El artículo 566-3 del código civil de Cataluña señala en su n. ${ }^{\circ} 3$ que "el único titular de ambas fincas puede extinguirla y obtener su cancelación en el Registro de la Propiedad, sin perjuicio de terceras personas".

70 Por ejemplo, si el propietario había arrendado el predio dominante, no puede dejar sin efecto la servidumbre que favorece a este último, pues mientras exista el interés del arrendatario, la servidumbre no se extinguirá. Dicho de otro modo, si el propietario extingue por acto jurídico unilateral la servidumbre, este acto le será inoponible al arrendatario. 
arbitrio. En cambio, habiendo nacido dicho interés, no pude eliminar la destinación efectuada, subsistiendo esta como servidumbre.

En todo caso, esta relación entre los efectos del principio nemini res sua servit iure servitutis y la concurrencia o no de intereses de terceros es del todo lógica, pues el principio tiene por base, como se ha visto, el derecho de dominio, el cual permite al propietario de dos predios el pleno uso, goce y disposición de los mismos, sin que para ello requiera de otros derechos adicionales al dominio. De modo que puede establecer todos los servicios que quiera entre dichos predios, así como eliminarlos también cuando lo estime conveniente. Es la presencia de un interés jurídico de tercero sobre uno de los predios lo que comporta un cambio de situación y, consecuencialmente, un cambio en la naturaleza jurídica del servicio.

Así las cosas, lo que dispone el principio, en realidad, es que "ninguno necesita de un derecho de servidumbre para servirse de cosa totalmente propia o exenta de limitaciones". A contrario sensu, "todos necesitan de un derecho de servidumbre para servirse de cosa parcialmente propia o limitada".

Es en este punto donde Cuadrado en realidad coloca el acento para fundamentar su opinión: si existe o no la posibilidad de ejercitar iure dominii las facultades que la servidumbre entrega. Si existe, no necesita de servidumbres, lo que se traduce en un beneficio para el propietario. Empero, este se debe mantener una vez que se produzca un cambio en su situación jurídica. Este cambio tiene lugar cuando no exista ya, aunque sea temporalmente, la posibilidad de ejercitar iure dominii algunas de las facultades que una servidumbre le podría entregar. Luego, la mantención del beneficio se consigue con el reconocimiento de que los servicios establecidos en el entretanto entre los predios adquirieron el carácter de servidumbres con la concurrencia de un derecho respecto de la cosa, que precisamente limita las facultades del propietario. Si así no ocurre, ese beneficio inicial termina no siendo real. De ahí la necesidad de que se proyecte luego del hecho transmiticio o dispositivo respectivo.

Ahora bien, el interés jurídico de terceros se manifestará en derechos para estos. Sin embargo, preferimos esta noción más amplia pues dichos derechos podrían ser de muy variada naturaleza: derechos de propiedad parcial (copropiedad); derechos reales propiamente desmembrados del dominio (p. ej., usufructo, uso o habitación); derechos reales de garantía (hipoteca); derechos reales simplemente limitativos (como el derecho de conservación introducido en Chile por la Ley 20.930); derechos personales derivados de variados contratos que pudieran celebrarse respecto de uno de los predios (como el arrendamiento); derechos que pudieran ejercer órganos públicos representando el interés de la comunidad derivados de actos administrativos que aprueban loteos o proyectos de urbanización que contemplan servicios establecidos unilateralmente por el propietario; derechos de terceros fundados en estos actos, admitiéndose el ejercicio de acciones judiciales; etc.

En todo caso, el interés jurídico de terceros que pueda concurrir respecto de uno de los predios no se identifica necesariamente con una ventaja, pues dicho interés puede tener lugar sobre el predio dominante o sobre el predio sirviente. 
De manera que en el primer caso, el tercero gozará de la utilidad que le concederá el servicio transformado en servidumbre activa; en el segundo caso, deberá soportar el gravamen. Mas, si el predio respecto del cual tiene interés el tercero es el predio dominante, significa que dicho tercero será beneficiado con la oponibilidad del derecho real de servidumbre, la cual podrá deducir contra el mismo propietario (del predio sirviente) así como contra otros terceros.

Que el tercero en este caso pueda beneficiarse de la oponibilidad, incluso contra el propietario, en ningún caso debe entenderse como una contradicción de la afirmación de que el principio nemini res sua servit iure servitutis es un beneficio para el propietario y no una limitación. Lo que ocurre es que esta oponibilidad, que ahora favorece al tercero, constituye en definitiva la consecuencia jurídica del beneficio económico perseguido por el propietario en el momento de establecer el servicio. Al respecto debe recordarse que el dueño unilateralmente estableció el servicio precisamente con la finalidad de otorgarle al predio favorecido una mejora y que, también en forma unilateral, podía haberla dejarlo sin efecto antes de que concurriera el interés del tercero. Si no procedió a esto último, se debe presumir que ello se debió a la presencia de alguna ventaja económica que de la mantención del servicio obtenía.

Por ejemplo, piénsese en el caso en que el propietario requiere solicitar un mutuo de dinero y constituir una hipoteca en favor del mutuante como garantía de pago. El servicio establecido en favor de uno de los predios puede significar un mayor valor del mismo, permitiéndole contar con una mejor garantía y en consecuencia obtener un préstamo en dinero superior. Igualmente, la existencia del servicio pudo haberle permitido cobrar una mayor renta por el arrendamiento del predio favorecido. En ambos casos, tanto el acreedor hipotecario como el arrendatario habrían estado dispuestos a estipular una mayor contraprestación por la seguridad de que adquirirían un derecho (real o personal respectivamente) respecto del predio dominante, en cuyo favor existiría una servidumbre (derecho real) de la cual podrán gozar erga omnes mientras dure el correspondiente derecho. Claro, porque además de oponérsela al dueño del predio que otorgó el derecho (y que es además propietario del sirviente), podrían hacerla valer ante el sub adquirente, arrendatario o usufructuario del predio sirviente.

En cambio, de seguirse la doctrina tradicional que no considera enajenación la adquisición de derechos reales o personales respecto de uno de los predios, al propietario se le reconoce como facultado para dejar sin efecto unilateralmente el servicio, aún vigente la hipoteca o el arrendamiento, en razón de no haber adquirido el carácter de servidumbre, actuación que perjudicaría el interés de los terceros titulares de derechos sobre el predio dominante (lo que de paso contradice la regla general7 ${ }^{\mathrm{I}}$ ). Por lo tanto, en los ejemplos, ni el mutuante estaría dis-

7 I El interés de los terceros es por regla general protegido en los ordenamientos jurídicos, modificando en su favor los efectos que producen las instituciones jurídicas. Es, por ejemplo, lo que 
puesto a prestar más dinero ni el arrendatario a pagar una mayor renta, todo lo cual redunda en definitiva en un perjuicio para el propietario de los dos predios. Es decir, el principio nemini res sua servit iure servitutis, en vez de beneficiar al propietario, finalmente lo perjudica. Es tan clara la cuestión que incluso autores con una postura distinta a la planteada en este trabajo no pueden sino aceptar esta realidad ${ }^{72}$.

En síntesis, en materia de DPF, el criterio que determina el momento en que el servicio establecido por el dueño continúa como servidumbre es la concurrencia de un interés jurídico de tercero respecto de uno de los predios entre los cuales su propietario estableció un servicio, conforme la correcta aplicación del principio nemini res sua servit iure servitutis. Ello exige necesariamente interpretar con amplitud el concepto de "enajenación" en esta materia, comprendiendo dicho concepto cualquier acto que importe el surgimiento del referido interés.

\section{Propiedad sobre cosas incorporales en el sistema jurídico chileno y colombiano}

La interpretación avanzada en orden a que el servicio adquiere el carácter de servidumbres cada vez que se conceda un derecho real o personal en favor de terceros sobre uno de los predios, se opondría a la definición de servidumbre, en cuanto los predios deben ser de distinto dueño (arts. 820 c.c.ch. y 879 c.c.col.). Mas, hoy en día tanto el dominio como las servidumbres resultan conceptos desmaterializados (o espiritualizados), sin perjuicio de que puedan en última instancia hacerse efectivos sobre una cosa corporal.

En este sentido, conforme a nuestros códigos civiles, sobre las cosas incorporales, o sea, derechos reales y personales, hay también una especie de propiedad, de acuerdo a los artículos 583 c.c.ch. y 670 c.c.col. Adicionalmente los artículos 582 c.c.ch. y 669 c.c.col. hacen sinónimos los conceptos de dominio y propiedad.

ocurre en nuestros sistemas civiles con las cláusulas de no enajenar, a las cuales expresamente se les da valor cuando existe un interés de terceros comprometido. En Chile, véanse los artículos 75 I, 793, I I 26 y I 432 n. ${ }^{\circ}$ I c.c. En Colombia, el artículo 8 ro no replicó la primera parte del inciso segundo del artículo $75 \mathrm{I}$ citado, correspondiendo los otros respectivamente a los artícu$\operatorname{los} 85^{2}$, i 184 y I 489 n. ${ }^{\circ}$ i c.c. Asimismo, si bien lo accesorio sigue la suerte de lo principal, de manera que extinguido el crédito se extinguen también las garantías y demás derechos anexos, modernamente códigos civiles comparados recogen expresamente en materia de obligaciones que la confusión de las calidades de deudor y acreedor no perjudica a terceros que hayan adquirido los derechos reales de usufructo o prenda sobre el crédito (arts. I 254 c.c.it.; 87 I n. ${ }^{\circ}$ I c.c.por.). Tampoco la confusión respecto a la calidad de arrendador perjudica al subarrendatario (art. I695 c.c.per.). Por tanto, aunque el derecho principal se extinga por confusión, la existencia de intereses de terceros lleva al resguardo de estos últimos por parte del legislador.

72 Así, Díaz, Servidumbres, cit., 308, para el caso de confusión en la propiedad de dos predios entre los cuales hay una servidumbre, y frente al perjuicio que significaría para el titular del derecho real de garantía la extinción consecuencial de esta, reconoce que "es verdad que la situación no se puede alterar, porque perjudica al titular de la hipoteca y al tercero posible adjudicatario, si aquella se ejecuta". 
En Chile, estas novedosas disposiciones frente a los códigos que les sirvieron de fuente 73 constituyeron la base del desarrollo en doctrina de la propiedad sobre derechos ${ }^{74}$. Y si bien la idea ha tenido sus detractores 75 , lo cierto es que desembarcó primero sin contención en los fallos de los tribunales de justicia, para luego alcanzar rango constitucional en el año 1976 a través del Acta Constitucional n. ${ }^{\circ}$ 3 del Gobierno militar de la época ${ }^{76}$. Esta, en su artículo r. ${ }^{\circ}$ n. ${ }^{\circ}$ i 6 , garantizó "El derecho de propiedad en sus diversas especies sobre toda clase de bienes, corporales o incorporales". La norma fue recogida en el artículo I9 n..$^{\circ} 24 \mathrm{de}$ la Constitución de 1980 , consagrando definitivamente el derecho de propiedad sobre las cosas incorporales 77 .

Si bien en Colombia no ha tenido una recepción tan explícita en el texto de la Carta Fundamental, el Tribunal Constitucional ha llegado a la misma conclusión, definiendo la propiedad privada "como el derecho real que se tiene por excelencia sobre una cosa corporal o incorporal, que faculta a su titular para usar, gozar, explotar y disponer de ella, siempre y cuando a través de su uso se realicen las funciones sociales y ecológicas que le son propias" ${ }^{8}$. Esta definición ha tenido desde luego por fundamento la Constitución Política de I99I, pero por sobre todo, en lo que nos interesa, los artículos 669 y 670 c.c.col. ( 582 y 583 c.c.ch.).

Entonces, si la propiedad sobre los derechos reales y personales ha sido aceptada por el sistema jurídico que Chile y Colombia comparten (sin perjuicio

73 El origen de la disposición se encuentra sustancialmente en el concepto romano de quasi dominium, terminología que inclusive usó Bello en el artículo 688 del proyecto de 1853 , antecedente del definitivo artículo 583 c.c.ch. Véase Barrientos Grandon, J., Código civil, t. i, Santiago, Legal Publishing, 201 2, 475 .

74 Claro Solar, Explicaciones, cit., De los bienes, vol. III, t. 6, n. ${ }^{\circ}$ 286, 30 I. Y el mismo autor se encargaba hace ya casi un siglo de destacar las bondades de la idea de la propiedad sobre derechos construida a partir del artículo 583 c.c., lo que implicaba aceptar el derecho de propiedad sobre el derecho de propiedad: "la doble propiedad de que la cosa pasa a ser objeto, se percibe con toda claridad intelectualmente, mientras que se presenta confusa si la consideramos materialmente [...]. La ciencia jurídica no pierde, gana, pues, con estas abstracciones que dan claridad y nitidez a las nociones de derecho". Claro Solar, Explicaciones, cit., De los bienes, vol. iII, t. 6, n. ${ }^{\circ}$ 287, 305. La propiedad sobre derechos tuvo un particular desarrollo en la segunda mitad del siglo $\mathrm{xx}$, a fin de impedir la modificación de los contratos mediante leyes retroactivas, postura reforzada mediante el recurso de protección constitucional. Cfr. López Santa María, J. y EloRriaga de Bonis, F., Los contratos. Parte general, Santiago, Legal Publishing, $2017^{6}$, 304 Ss. (véase en nota 445 bibliografía citada por el autor).

75 No les convence la idea de la propiedad sobre derechos personales a López y Elorriaga, Los contratos, cit., 3 I 3 .

76 Decreto Ley I552, publicado el I3 de septiembre de I976.

77 Se trata de una posición dogmática asentada y reiterada permanentemente por los tribunales, resultando destacable que sobre los derechos personales también existe derecho de propiedad. Puede así constatarse en la síntesis jurisprudencial confeccionada por Barrientos, Código civil, cit., 475 y 476; y por De la Maza Gazmuri, Í., Código civil. Sistematizado con jurisprudencia, t. I, Santiago, Thomson Reuters, 201 5, 593 y 594.

78 Sentencia C-r 89-06. Otras sentencias han aceptado la misma concepción sobre propiedad, p. ej., C-4IO-I 5, T-537-92, C-I33-09. 
de los códigos civiles que replican sus normas y la aceptación creciente de la noción por la doctrina comparada79), y tanto la doctrina mayoritaria como la jurisprudencia están de acuerdo con ella y la aplican en la práctica, habrá que admitir todos sus efectos.

En este contexto, el titular del derecho real constituido sobre uno de los predios pertenecientes a un mismo dueño, y entre los cuales este ha establecido un servicio, o el titular de un derecho personal en idéntico caso, son dueños del respectivo derecho real o personal. Por tanto, la constitución de un derecho real o la concesión de un derecho personal sobre uno de los predios importan respecto del dueño de estos un acto efectivamente de enajenación. Hay una propiedad distinta al ius dominii original, que les es transferida a los titulares de los derechos, sea por voluntad del dueño de los pedios o por imposición de la ley. Esa propiedad tiene por objeto inmediato los derechos reales o personales respectivos, limitará el derecho real de dominio (predio jurídico) y se hará efectiva sobre alguno de los predios (materiales).

Por tanto, conforme a lo expresado, no es cierto que cuando se constituye un derecho real o se concede un derecho personal sobre uno de los predios no concurra el requisito de la ajenidad exigido por los artículos 820 c.c.ch. y 879 c.c.col., necesario para que estemos en presencia de una servidumbre. Estas disposiciones imponen como requisito que los predios sean "de distinto dueño" o, lo que es lo mismo, que recaigan sobre cada predio distintas propiedades. $\mathrm{Si}$ sobre uno de los predios se ha constituido un derecho real o se ha concedido un derecho personal, significa que junto con el titular del dominio de ambos predios concurre un dueño del respectivo derecho real o personal que tiene por objeto uno de estos. De manera que la existencia de dichos derechos determina que concurran jurídicamente sobre los predios materiales al menos dos propiedades heterogéneas y, por tanto, respecto de tales predios, diferentes dueños.

Cuestión distinta es la calidad de los derechos sobre los que recae dicha propiedad, pues evidentemente un derecho real tendrá un contenido disímil a un derecho personal, lo que se traduce en facultades y límites diversos para el titular, conforme la naturaleza del respectivo derecho, pero que no inciden en la propiedad. Respecto de ambas clases de derechos, tanto quien detenta un derecho real como quien detenta un derecho personal es en definitiva propietario de su derecho ${ }^{80}$. Por lo mismo, no influye en la cuestión que tales derechos sean temporales y se extingan por la llegada de un plazo o el cumplimiento de una condición pues, reiteramos, estas modalidades formarán parte del contenido del derecho y determinarán la calidad de la "cosa incorporal" objeto de la propiedad, sin modificar esta última. Lo

79 P. ej., en Francia, se afirma un creciente favor de la doctrina respecto de la propiedad sobre derechos. Ver MeIller, É., La notion de servitude, Paris, LGDJ, 20 I 2, 39 I.

80 Ocurre lo mismo entre la propiedad sobre cosas corporales y la propiedad sobre cosas incorporales. El derecho es idéntico pero no se presta de la misma forma dada la naturaleza del objeto. Claro Solar, Explicaciones, cit., De los bienes, vol. III, t. 6, n. ${ }^{\circ} 285,300$. 
contrario sería pretender, por ejemplo, que la propiedad sobre cosas consumibles es distinta a la propiedad sobre cosas no consumibles, lo que, sabemos, no ocurre. En ambos casos la propiedad es idéntica, pero las facultades jurídicas, materiales y temporales que pueden ejercerse sobre la cosa se encuentran determinadas por la naturaleza de esta.

Así entonces, la contradicción que destacamos en Guilarte quedaría completamente superada, pues se cumpliría con la letra del artículo 54 I c.c.es., así como con la literalidad de cualquier código civil que exija la "separación de la propiedad". En efecto, bajo los términos de la doctrina actual de la propiedad sobre derechos, la frase del código civil español "al tiempo de separarse la propiedad de las dos fincas" adquiere un nuevo sentido, pues la constitución de derecho real o la concesión de un derecho personal sobre uno de los predios importa jurídicamente la separación de la propiedad de las dos fincas, al menos parcialmente. Como hemos dejado en claro, a partir de ese momento, sobre una de las fincas concurrirá una suerte de copropiedad, pues junto al propietario de la finca concurrirá el propietario del derecho real o personal respectivo, y todas estas propiedades en última instancia otorgan facultades sobre el mismo bien corporal: uno de los predios. Y si, como vimos, la doctrina está conteste en que la configuración de una copropiedad tradicional sobre uno de los fundos transforma el servicio en servidumbre, deberá aceptarse que esta doble propiedad de derechos sobre uno de los fundos necesariamente producirá el mismo efecto.

\section{La ampliación del concepto de predio incluye cosas incorporales}

Adicionalmente a lo expresado, se debe considerar que las servidumbres activas son un derecho real (arts. 577 c.c.ch. y 665 c.c.col.) y, por tanto, una facultad que se adiciona a los poderes que el dominio concede al titular del predio dominante. Correlativamente, las servidumbres pasivas, en cuando gravamen, son una limitación al dominio del titular del predio sirviente (arts. 732 , n. ${ }^{\circ} 3$ c.c.ch. y 793, n. ${ }^{\circ} 3$ c.c.col.), que se traduce en obligaciones para su titular. De manera que jurídicamente estamos en realidad en presencia de una utilidad y un gravamen para el dominio respectivo, y no materialmente para los predios; es decir, las servidumbres son utilidades en favor del derecho realde dominio sobre el predio dominante y gravámenes que limitan el derecho real de dominio sobre el predio sirviente. Lo beneficiado o deteriorado son los derechos respectivos, y no los predios, aun cuando tengan un efecto material en estos. El punto ya ha sido advertido por la doctrina que se ha ocupado de la cuestión $^{8 \mathrm{I}}$. Vistas las cosas desde esta óptica, lo dominante es un derecho de

8I Con razón, Segura afirma que servidumbre "es el gravamen impuesto a la propiedad en utilidad de un predio, en beneficio de otra propiedad u obra de distinto dueño”. Segura Riveiro, F., 
dominio y lo sirviente es otro derecho de dominio, de modo que "los predios" en realidad parecen hoy en día ser directamente los derechos y no la porción de terreno o edificio objeto de los mismos y sobre los que ellos se ejercen.

Este resultado conceptual que la moderna abstracción jurídica admite, ha llevado a que la noción de "predio" en materia de servidumbres se haya ampliado a las cosas incorporales en Chile así como en otras legislaciones latinoamericanas. Esta ampliación se traduce en admitir la constitución de servidumbres en favor de derechos reales en calidad de "predios" dominantes, como asimismo que se puedan gravar dichos derechos en calidad de "predios" sirvientes. Los ejemplos más claros de este fenómeno se encuentran en el derecho de minería y en el derecho de aguas.

Respecto al primero, se debe tener presente que el sistema minero se basa en la reserva de la propiedad de las minas que se encuentran en predios privados en favor del Estado, de modo que es este quien "concede" a los particulares, temporal o indefinidamente, un derecho relativo a las sustancias minerales, como son los de exploración y explotación. En Chile, Perú, Bolivia, Nicaragua, Honduras, Costa Rica y Guatemala, las concesiones mineras se califican expresamente como derecho real inmueble ${ }^{82}$, calificación que también puede considerarse para Argentina ${ }^{83}$ ). La ley en Ecuador califica en cambio la concesión como un derecho personal ${ }^{84}$, naturaleza aplicable a las concesiones en Colombia, Uruguay, Paraguay y Panamá ${ }^{85}$.

Pero, sean las concesiones derechos reales o personales, lo cierto es que todas las legislaciones citadas han debido enfrentar el mismo problema: los concesionarios solo tienen derecho a la exploración o explotación de los minerales que, si bien son estatales, se encuentran en terrenos habitualmente privados y ajenos a los concesionarios y al Estado. En razón de ello, necesitan de derechos adicionales que les permitan acceder físicamente a los yacimientos, alcanzarlos, extraer los minerales, procesarlos y transportarlos a otras zonas geográficas, además de múltiples otras actividades relacionadas. La solución al problema ha sido la misma: imponer, o bien permitir imponer sobre los terrenos privados ajenos,

"Las servidumbres en el derecho de aguas", Revista de Derecho, n. ${ }^{\circ}$ 209, 200I, I87, 192 y 194.

82 Arts. $2 .{ }^{\circ}$ de la Ley Orgánica Constitucional de Minería; $2 .{ }^{\circ}$ c. de minas ch. y $5 .{ }^{\circ}$ de la Ley 19.657 en Chile; $4 .^{\circ}$ y I.$^{\circ}$ c. de minas bol.; r.$^{\circ}$ de la Ley General de Minería del Perú; I 5 de la Ley Especial sobre Exploración y Explotación de Minas de Nicaragua; 9. ${ }^{\circ}$ de la Ley General de Minería de Honduras; i 2 c. de minas de Costa Rica; y i 7 de la Ley de Minería de Guatemala.

$83 \mathrm{El}$ artículo I I c. de minas arg. se refiere a la propiedad respecto a las minas como distinta a la propiedad del terreno superficial y, por tanto, entiende que de la concesión nace un derecho real de dominio sobre ellas (las que son consideradas además inmuebles por el artículo I2).

84 Arts. 30 y 32 de la Ley de Minas ec., además de tener por causa un contrato de concesión (art. 4I).

85 Según los artículos I 4 c. de minas col.; 2 y 8 I c. de minas ur.; 33 de la Ley de Minas par.; y $6 .^{\circ}$ y $8 .^{\circ}$ c. de recursos minerales pan., los derechos mineros nacen para su titular y son regulados mediante un contrato de concesión. 
servidumbres en favor de los derechos mineros ${ }^{86}$ (normalmente contra el pago de una indemnización), que les permitan a los titulares de estos las referidas actividades.

Como se aprecia, mientras el terreno superficial en cuyo subsuelo están los minerales asume el carácter de predio sirviente, el predio dominante, por el contrario, no resulta ser ningún "predio", ningún "fundo" ni ninguna "heredad", sino la concesión minera respectiva; esto es, el derecho real o personal según corresponda. No en vano algunas legislaciones califican expresamente a los derechos mineros de derechos "inmuebles" 87 (sin perjuicio de que las minas son tradicionalmente consideradas inmuebles y por tanto la misma naturaleza tienen los derechos sobre ellas). De manera que las servidumbres en favor de concesiones mineras se constituyen de todos modos en utilidad de un "inmueble".

Aún más, servicios constituidos sobre el terreno respecto de los cuales existe una concesión pueden resultar necesarios para el ejercicio de otra concesión otorgada sobre minerales ubicados en terrenos contiguos o relativamente cercanos. La facultad para el nuevo concesionario de aprovechar dichos servicios redundará en una molestia para el primer concesionario.

Si bien hay diferencias entre las distintas legislaciones en cuanto a la solución jurídica a esta situación, la tendencia es imponer al primer concesionario la carga de permitir a los nuevos concesionarios beneficiarse de los servicios de que goza. En ocasiones, la ley respectiva simplemente entiende que lo afectado en la situación descrita es el terreno concesionado inicialmente con servidumbres en favor de otras concesiones; o bien, que estas se aprovechan de servidumbres ya establecidas $^{88}$. Otras veces, en cambio, se da a las concesiones mineras ya constituidas la calidad de predio sirviente ${ }^{89}$.

86 En Chile, arts. 2. ${ }^{\circ}$ de la Ley Orgánica Constitucional de Minería, I 20 c. de minas ch., y 26 de la Ley 19.657. Asimismo, arts. 56 c. de minas bol.; 3 I c. de minas ur.; r66 c. de minas col; 146 c. d eminas arg.; 46 c. de minas de Costa Rica; I9, iv, de la Ley de Minas mex.; 54 de la Ley de Minas par.; 6, letra b) y 72 ss. de la Ley de Minas gua.; 22, 27 ss. de la LGM.hon.; I 23 c. de recursos minerales pan.; 50 de la Ley Especial sobre Exploración y Explotación de Minas de Nicaragua; y $37 \mathrm{n}^{\circ} 3$ de la LGM.per. (aunque en este país se entienden partes integrantes de la concesión minera las labores ejecutadas tendientes al aprovechamiento de tales sustancias y todos los bienes de propiedad del concesionario que estén aplicados de modo permanente al fin económico de la concesión); y, i 5 y roo de la Ley de Minas ec. (igual situación que Perú, art. 59 Ley de Minas ec.).

87 Arts. $2 .{ }^{\circ}$ c. de minas ch.; $4 .{ }^{\circ}$ c. de minas bol.; $9 .{ }^{\circ}$ LGM Perú; $3 .{ }^{\circ}$ c. de minas ur.; y I 2 c. de minas arg.

88 Arts. 148 y 149 c. de minas arg.

89 Arts. I 26 y I 27 c. de minas ch.; 37 n. ${ }^{\circ} 5$ LGM Perú; IO2 de la Ley de Minas ec.; y I 85 c. de minas col. En este sentido, Ossa Bulnes, Juan Luis, Tratado de derecho minero, t. I, Jurídica, Santiago, $2007^{4}$, p. 466. Guzmán señala sobre esta posibilidad que es evidente que no pueden constituirse servidumbres sobre una concesión minera, de modo que la expresión estaría tomada por el código de minas de Chile en el sentido material del "sólido", dado que las servidumbres solo se podrán ejercer sobre una cosa corporal. GuZmán BRITo, A., Las cosas incorporales en la doctrina y en el derecho positivo, Santiago, Jurídica de Chile, $2006^{2}$, p. 225. 
Esta última alternativa implica admitir que pueda tener el carácter de predio dominante o de predio sirviente una cosa incorporal, lo que se traduce en definitiva en una ampliación del concepto de predio del derecho común (arts. 568 c.c.ch. y 656 c.c.col.), ensanchamiento del cual participa la doctrina90.

Lo dicho en precedencia tiene igualmente lugar en todas aquellas materias en que, por reenvío del legislador, resultan aplicables las disposiciones sobre minería ${ }^{91}$.

En cuanto al derecho de aguas, idéntica situación se presenta al menos en Chile respecto al derecho real de aprovechamiento de aguas, el cual por regla general tendrá por título una concesión administrativa. Para su efectiva explotación, el legislador admite la constitución de servidumbres en su favor, convirtiéndolo en predio dominante (arts. 69 y ss. c. de aguas ch.). Asimismo, este derecho sería susceptible de ser gravado en favor de otros de igual naturaleza, con lo cual puede también adquirir la calidad de predio sirviente. $\mathrm{Y}$ aunque no es coherente admitir esta última posibilidad en materia de minería y rechazarla en el ámbito de las aguas, la doctrina nacional ha mostrado mayor reticencia frente a este reconocimiento legislativo ${ }^{2}$.

Dado el origen y desarrollo histórico de las servidumbres, el concepto de "predio" evidentemente siempre se ha identificado con cosas corporales (fundos, heredades, casas, edificios, etc.). La posibilidad de que recaigan sobre cosas incorporales constituye una abstracción moderna y aún en desarrollo en la mayoría de las legislaciones. Es por ello que para explicar casos como los descritos, la doctrina comparada recurrió a la noción de servidumbres "sin predio

Lira, en relación con el artículo artículo 568 c.c.ch. (656 c.c.col.), precisamente admite que aun cuando en materia minera los predios dominantes y sirvientes no se acomodan al concepto de "predio" de dicha disposición, es claro que para la legislación chilena y extranjera el concepto es más amplio y comprensivo de un sinnúmero de bienes diferentes a "casas y heredades". LiRA Ovalle, S., Curso de derecho de minería, Santiago, Jurídica, $2012^{6}{ }^{6}$ i 78 . En el mismo sentido, Peña y Lillo Delaunoy, C., De las servidumbres mineras, Santiago, Metropolitana, 2014, 25 y 68; Ossa, Tratado de derecho minero, cit., 464, 465 y 482; Ruiz Bourgeors, J., Instituciones de derecho minero chileno, t. II, Santiago, Jurídica, i949, 24. Vergara Blanco, A., Instituciones de derecho minero, Santiago, Abeledo-Perrot, 201o, 459 y 462 ; Vergara Blanco, A., "Constitución de servidumbres a favor de instalaciones eléctricas", Revista Chilena de Derecho, 25, 2, 1998, 33 I; Vergara Blanco, Derecho eléctrico, Santiago, Jurídica de Chile, 2004, 230.

9I Por ejemplo, en Chile, a las concesiones de transporte de hidrocarburos mediante "oleoductos" y a los derechos de aprovechamiento adquiridos para tales efectos, según el artículo $8 .^{\circ}$ del Decreto con Fuerza de Ley I, Minería, I987. Igualmente, a las concesiones de distribución y transporte de gas ("gasoductos"), y a su aprovechamiento conforme legislación especial que las regula, de acuerdo al artículo I 2 inciso 2. ${ }^{\circ}$ de la Ley de Servicios de Gas (Decreto Ley 323 de I93I). La jurisprudencia ha ratificado esta aplicación de las disposiciones sobre servidumbres mineras. Cfr. CS, 27 de agosto de 2009, ENAP Refinerías S.A. con Moure Oportot, Rol 29042009, CL/JUR/665/2009.

92 Vergara Blanco, Instituciones, cit., 478 y 479; Guzmán, Las cosas incorporales, cit., 225; Vergara Duplaquet, C., "Normas por las cuales se rigen las servidumbres en materia de derecho de aguas", en Vergara Blanco, A. (dir.), Código de Aguas comentado: doctrina y jurisprudencia, Santiago, Abeledo-Perrot, 201 I, 285. 
dominante"93, especialmente en el ámbito del derecho administrativo, donde se han identificado estos casos fundamentalmente con las servidumbres legales de utilidad pública94. Es decir, en vez de entender como "predio" el derecho en cuyo favor la ley permite la constitución de servidumbres, la tendencia ha sido desconocer la existencia de un predio en cuya utilidad se impuso el gravamen. Esta manera de exponer el fenómeno jurídico ha tenido recepción en Colombia $^{95}$ y entre los doctrinarios chilenos ${ }^{96}$. Por el contrario, dada la necesidad de un gravamen sobre un predio, una doctrina sobre servidumbres sin predio sirviente nunca ha sido desarrollada.

La admisión legislativa de servidumbres sobre cosas incorporales, esto es, en favor de derechos reales o personales, o bien que gravan derechos reales o personales, elimina la idea de servidumbres sin predio dominante o eventualmente de servidumbres sin predio sirviente. Pero por sobre todo, y en lo que aquí nos interesa, ratifica que el otorgamiento de derechos reales o personales respecto de uno de los predios entre los cuales su dueño estableció un servicio convierte a este en servidumbre por DPF. Ello no solo porque el titular del respectivo derecho es propietario del mismo, generando efectivamente una separación de la propiedad, según se vio en la letra anterior, sino porque además ese derecho, en cuanto tal, puede hoy constituir un predio dominante o un predio sirviente en razón de la ampliación del concepto de predio que ha tenido lugar en el derecho latinoamericano. Sobre esta ampliación, y el ensanchamiento consecuencial del concepto de enajenación para efectos de la aplicación de la DPF, ya nos habíamos pronunciado en trabajos precedentes a este 97.

93 Meiller, La notion de servitude, cit., 5 I 3 ss. Según Biondi, conforme el tenor de las disposiciones del código de 1942 , la noción de servidumbres legales sin predio dominante se descarta, pues la noción de servidumbre se restringiría únicamente a las relaciones entre fundos, estructura no presente en las "antiguas". Biond, Las servidumbres, cit., n. ${ }^{\circ} 295$, I 289.

94 Sin perjuicio de quienes han sostenido la ampliación del concepto de predio en el ámbito de las servidumbres administrativas, en vez de la falta de predio dominante. En este sentido, De LA Fuente Pérez, G., Las servidumbres administrativas: doctrina, legislación y jurisprudencia, memoria para optar al grado de licenciado, Santiago, Universitaria, i 962, 8 I y 82.

95 Arévalo, Los bienes, cit., 24I; Velásquez Jaramillo, Bienes, cit., 453; Restrepo Rodríguez, T., La servidumbre petrolera, Estudio de la Ley I 274 de 2009 a partir del derecho civil, Bogotá, Universidad Externado de Colombia, 20 I4, 79 y 82. Este último autor reemplaza al predio dominante como beneficiario por la "industria petrolera", no obstante reconocer que el beneficio es para quien desarrolle la actividad minera, en virtud de un contrato o una resolución del Ministerio de Minas y Energía. Es decir, quien goza del derecho correspondiente. La explicación resultaría más precisa y consistente, a nuestro entender, si se hubiese afirmado que el predio dominante es el derecho respectivo, reconocido por el derecho común como cosa, aunque incorporal.

96 Vodanovic, Tratado de los derechos reales, cit., t. I, n. ${ }^{\circ}$ I 35, IO2; Claro Solar, Explicaciones, cit., De los bienes, vol. iv, t. 9, n. ${ }^{\circ}$ I 399, 96; PeÑallillo Arévalo, D., Los bienes, Santiago, Jurídica de Chile, reimp. 2016, n. $^{\circ} 253,490$.

97 Rosso Elorriaga, G. F., "Ampliación del concepto de 'predio' en materia de servidumbres y posibles efectos", en Turner, S. y Varas, J. A. (eds.), Estudios de derecho civil IX, Santiago, Legal Publishing, 2014, 2 I 5-234. 


\section{Conclusiones}

Conforme a todo lo dicho, podemos concluir lo siguiente:

a. En virtud del principio nemini res sua servit iure servitutis, ninguna cosa propia puede servir a su dueño por derecho de servidumbre. Las consecuencias de esto son: que al propietario de dos predios le está vedado constituir servidumbres entre ellos, pudiendo solo establecer servicios de hecho; que estos se transforman en servidumbres por "destinación del padre de familia", cuando uno o ambos predios son enajenados o adjudicados a personas diferentes, conforme a lo dispuesto en los artículos 88 I c.c.ch. y 938 c.c.col.; y que las servidumbres existentes entre dos predios se extinguen por la reunión de la propiedad de estos en una sola persona, las cuales reviven si el único dueño las mantiene como servicios y posteriormente se divide nuevamente el dominio por enajenación o adjudicación, todo ello según disponen los artículos 885 n. ${ }^{\circ} 3^{\circ}$ c.c.ch. y 942 n. ${ }^{\circ} 3$ c.c.col.

b. El principio y consecuencias señaladas, producirían una serie de dificultades prácticas perjudiciales para los propietarios, entre las cuales destaca la imposibilidad de lograr una reserva de preferencia. Esta imposibilidad se traduce en que no pueden los dueños oponer los servicios que hayan establecido entre sus predios como servidumbre, a quienes adquieren derechos reales o personales sobre estos, o bien los titulares de estos hacerlos valer ante el propio dueño o ante otros terceros. Esta inoponibilidad importa en definitiva pérdidas económicas para los propietarios.

c. La revisión de las referidas dificultades permite concluir que el problema esencial a su respecto es la "oportunidad" en que se transforman en servidumbre los servicios que el propietario ha establecido entre sus predios. De manera que la solución a las referidas dificultades se encontraría en alterar dicha oportunidad. Las servidumbres de propietario y la constitución de servidumbres mediante acto jurídico unilateral condicional constituyen propuestas de solución en este sentido.

d. Las servidumbres de propietario resuelven la cuestión de la oportunidad simplemente derogando el principio nemini res sua servit iure servitutis. Así, hay servidumbre desde que el propietario la constituye entre sus predios, aunque no haya separación en el dominio de estos. Además de tratarse de una solución que solo es posible si el legislador modifica los códigos civiles, sustancialmente importa admitir un absurdo: al propietario le resultan insuficientes las facultades que le concede el ius dominii, resultándole necesarios otros derechos reales para la plena satisfacción de sus intereses.

e. La constitución de servidumbres mediante acto jurídico unilateral condicional pretende superar el problema de la oportunidad a través del efecto retroactivo de las condiciones cumplidas: el acto solo produce efecto, y retroactivamente desde la fecha de su celebración, cuando se cumple la condición consistente en la separación del dominio de los predios vinculados. Sin embargo, 
esta interpretación presenta severos defectos. Por una parte, habría que aceptar un concepto muy discutible como es el de conditio iuris; por otra, en nuestro sistema jurídico la condición solo puede estar pendiente por un tiempo determinado, lo que en vez de beneficiar al propietario, lo perjudicaría aún más cuando la condición se entienda fallida. Pero, por sobre todo, no resuelve por sí misma los casos en que, en vez de transferirse o transmitirse el dominio, se conceden derechos reales o personales sobre uno de los predios entre los cuales el servicio se encuentra establecido.

f. El verdadero problema, a nuestro parecer, y por tanto donde se debe buscar la solución, es la interpretación restrictiva del concepto de "enajenación" contenido en los artículos 88 I c.c.ch. y 938 c.c.col. y que se aplica tradicionalmente en materia de DPF. No obstante el ensanchamiento que el término ha tenido en el tiempo, la tendencia ha sido excluir del mismo la constitución de derechos reales o la concesión de derechos personales, admitiendo la transformación en servidumbres de los servicios establecidos solo cuando hay separación total en el dominio de los predios.

g. Creemos que esta restricción es equívoca, debiendo releerse la referencia a la enajenación para la aplicación de la DPF. Primeramente, porque el fundamento del principio nemini res sua servit iure servitutis no es otro que el beneficio del dueño. Si los servicios que establece este entre predios de su propiedad no son servidumbres es porque no las necesita, pues le basta su ius dominii. Si, por el contrario, le son útiles, deben concedérsele las servidumbres. Si esto último se le niega, significa que el principio no es un beneficio para el dueño, sino una limitación a su propiedad. De ahí que el beneficio, para que sea tal, debe extenderse objetivamente a cualquier hecho que importe la transmisión o disposición voluntaria o involuntaria de derechos, sean reales o personales.

h. En coherencia con lo anterior, el criterio que debe determinar cuándo el servicio se transforma en servidumbre es la concurrencia de un interés jurídico de tercero respecto de uno de los predios. Es este interés el que le exige al propietario contar con un derecho real de servidumbre respecto del predio servido, que pueda oponer al tercero interesado o, eventualmente, a otros terceros; y es asimismo dicho interés el que exige al tercero contar con un derecho real de servidumbre que pueda oponer al propietario del predio que sirve o bien, eventualmente, a otros terceros.

i. El entender que también hay enajenación para los efectos de la aplicación de la DPF cuando se constituyen derechos reales o se conceden derechos personales sobre uno de los predios no se contrapone en la actualidad al requisito de la ajenidad contemplado en los artículos 820 c.c.ch. y 879 c.c.col. Ello en razón de que hoy impera en el sistema jurídico chileno y colombiano el fenómeno de la propietarización de las cosas incorporales, incluso con rango constitucional. Así, el titular del derecho real constituido o del derecho personal concedido es dueño de su derecho. De manera que efectivamente se ha producido una separación de 
la propiedad sobre los predios entre los cuales el servicio fue establecido: por una parte, hay un dominio que se ejerce directamente sobre los predios y, por otra, un dominio sobre el derecho real o personal que se ejerce indirectamente sobre uno de los predios.

j. Una interpretación extensiva de enajenación en materia de DPF es plenamente coincidente con la ampliación que a su vez ha sufrido el concepto de predio a nivel legislativo en Chile y otros países latinoamericanos. En virtud de tal ampliación se admite la constitución de servidumbres en favor o sobre cosas incorporales. Por lo mismo, los servicios establecidos por el dueño entre sus predios (materialmente considerados) pueden perfectamente dar lugar a servidumbres en utilidad de los derechos reales o personales otorgados sobre uno de ellos, o bien a servidumbres que gravan esos derechos en beneficio de otro predio (materialmente considerado).

\section{Bibliografía}

Abeliuk Manasevich, R., Las obligaciones, Santiago, Legal Publishing, 20 I4.

Albaladejo, M., Derecho civil, Derecho de bienes, t. III, vol. 2, Barcelona, Bosch, I994.

Alessandri Rodríguez, A. y Somarriva Undurraga, M., Tratado de las obligaciones, ampliada y actualizada por Antonio Vodanovic Haklicka, Santiago, Jurídica de Chile, 200 .

Alonso Pérez, M. T., "Constitución y extinción de las servidumbres”, en Bayod, C. (ed.), Derecho civil patrimonial aragonés, Zaragoza, Institución "Fernando El Católico" (c.s.I.c.), 2013.

Arévalo Guerrero, I. H., Los bienes. Constitucionalización del derecho civil, Bogotá, Universidad Externado de Colombia, I9 2.

Arjona Guajardo-Fajardo, J. L., "El derecho de vuelo en nuestro ordenamiento (consideraciones a propósito de unas recientes resoluciones)", Revista Crítica de Derecho Inmobiliario, n. ${ }^{\circ} 664,200 \mathrm{I}$.

Barcia Lehmann, R., Lecciones de derecho civil chileno, De la teoría de las obligaciones, t. III, Santiago, Jurídica de Chile, 20 Io.

Barrientos Grandon, J., Código civil, t. i, Santiago, Legal Publishing, 20 i 2.

Beauvarlet, P., Les servitudes, Paris, Defrénois, 20 I 3. 
Bellod Fernández de Palencia, E., "Servidumbres: concepto, clases, caracteres, contenido de las servidumbres", en BAYOD, C. (ed.), Derecho civil patrimonial aragonés, Zaragoza, Institución "Fernando El Católico" (c.s.ı.c.), 20 I 3.

Biondi, B., Las servidumbres, trad. de la 2. a ed. por José Manuel González Porras, Granada, Comares, 2002.

Bonet Correa, J., La constitución de las servidumbres por signo aparente, Madrid, Consejo Superior de Investigaciones Científicas, I970.

Claro Solar, L., Explicaciones de derecho civil chileno y comparado, De las obligaciones, vol. v, t. Io, Santiago, Jurídica de Chile, 20 I 5.

Clemente Meoro, M., Derechos reales y derecho inmobiliario registral, Barcelona, Tirant lo Blanch, 200I.

Cuadrado Pérez, C., La servidumbre de propietario, Madrid, Colegio de Registradores de la Propiedad y Mercantiles de España, 2008.

Cuadrado Pérez, C., Constitución de servidumbre por signo aparente, Cuadernos de Derecho Registral, Madrid, 2007.

Cuneo Macchiavello, A., "El usufructo constituido con posterioridad a una hipoteca: su eficacia frente al acreedor", Revista de Derecho y Furisprudencia, 85,3, I 988 .

De la Fuente Pérez, G., Las servidumbres administrativas: doctrina, legislación y jurisprudencia, memoria para optar al grado de licenciado, Santiago, Universitaria, I962.

De la Maza Gazmuri, I., Código civil. Sistematizado con jurisprudencia, t. I, Santiago, Thomson Reuters, 2015.

Del Pozo Carrascosa, P.; Vaquer Aloy, A. y Bosch Capdevila, E., Derecho civil de Cataluña, Derechos reales, Madrid, Marcial Pons, 20 Iо.

Díaz Fuentes, A., Servidumbres, serventías y relaciones de vecindad, Barcelona, Bosch, 2004.

Ducci Claro, C., Derecho civil, Parte general, Santiago, Jurídica de Chile, 20 io. 
Enneccerus, L.; Kipp, T. y Wolff, M., Tratado de derecho civil, Derecho de cosas, t. $3 \cdot{ }^{\circ}$, vol. iI, B. Pérez y J. Alguer (trads.), Barcelona, Bosch, i 98 I.

García Alguacil, M. J., Consolidación y derechos reales en cosa propia, Granada, Comares, 2002.

García García, J. M., "Comentario a sentencia del TS de 2 I octubre i976", Revista Crítica de Derecho Inmobiliario, 529, I978.

Grosso, G. y Deiana, G., Le servitù prediali, t. i, Torino, utet, I955.

Guilarte Gutiérrez, V., La constitución voluntaria de servidumbres en el derecho español, Madrid, Montecorvo, I984.

Guzmán Brito, A., Las cosas incorporales en la doctrina y en el derecho positivo, Santiago, Jurídica de Chile, 2006.

Huber, E., Die eigentümerdienstbarkeit, ein Beitrag zu ihrer Rechtfertigung, Bern, Stämpfli, I902.

Jordano Fraga, F., "Prehorizontalidad y servidumbre de propietario", Revista de Derecho Notarial, I I 3-I I4, I98I.

Larraín Ríos, H., Teoría general de las obligaciones, Santiago, LexisNexis, 2005.

Lira Ovalle, S., Curso de derecho de minería, Santiago, Jurídica, 20 I 2.

Llácer Matacás, M. R., "La servidumbre sobre finca propia”, en Rebolledo Varela, Á. L. (ed.), Tratado de servidumbres, t. II, Navarra, Aranzadi, 20 I 3.

López Santa María, J. y Elorriaga de Bonis, F., Los contratos. Parte general, Santiago, Legal Publishing, 20 I 7.

Manresa y Navarro, J. M., Comentarios al código civil español, t. iv, Madrid, Reus, I972.

Mateo Borge, I., La servidumbre de propietario, Madrid, Marcial Pons, 2000.

MeIller, É., La notion de servitude, Paris, LGDJ, $20 \mathrm{O} 2$.

Meza Barros, R., Manual de derecho civil, De las obligaciones, Santiago, Jurídica de Chile, 2009. 
Ospina Fernández, G., Régimen general de las obligaciones, Bogotá, Temis, i 978.

Ossa Bulnes, J. L., Tratado de derecho minero, t. I, Santiago, Jurídica, 2007.

Peña y Lillo Delaunoy, C., De las servidumbres mineras, Santiago, Metropolitana, 20I4.

Peñailillo Arévalo, D., Los bienes, Santiago, Jurídica de Chile, 20 i 6.

Peralta Jiménez, C., Las servidumbres en Aragón. Disponible en: http://www. economistjurist.es/articulos-juridicos-destacados/las-servidumbres-en-aragon/ [Consultado el 5 de enero de 20I8].

Rebolledo Varela, Á. L., Tratado de servidumbres, t. i, Navarra, Aranzadi, 20 I 3.

Ramos Pazos, R., De las obligaciones, Santiago, LexisNexis, 2004.

Restrepo Rodríguez, T., La servidumbre petrolera. Estudio de la Ley 1274 de 2009 a partir del derecho civil, Bogotá, Universidad Externado de Colombia, 20 I4.

Rosso Elorriaga, G. F., "Las servidumbres discontinuas pueden adquirirse por 'destinación del padre de familia'. Reinterpretación del artículo 88 I del Código Civil”, en Barría, M. (ed.), Estudios de derecho civil XI, Santiago, Legal Publishing, 2016, 353-374.

Rosso Elorriaga, G. F., "Constitución de servidumbres sobre predio propio por acto jurídico unilateral del dueño: destinación formal del padre de familia y relectura del 'servicio aparente", Revista de Derecho Privado, 3 I, 20 I 6, I I I- I49.

Rosso Elorriaga, G. F., "Ampliación del concepto de 'predio' en materia de servidumbres y posibles efectos”, en Turner, S. y Varas, J. A. (eds.), Estudios de derecho civil $I X$, Santiago, Legal Publishing, 2014.

Rosso Elorriaga, G. F., "Destinación del padre de familia en las servidumbres”, en Basso, M. et al. (eds.), Sistema jurídico romanista y subsistema jurídico latinoamericano, Liber discipulorum para el profesor Schipani, Bogotá, Universidad Externado de Colombia, 20 I 3.

Ruiz Bourgeois, J., Instituciones de derecho minero chileno, t. II, Santiago, Jurídica, I949.

San Martín Devoto, D., Las servidumbres, Santiago, Conosur, I 998. 
Scaevola, Q. M., Código civil. Comentado y concordado extensamente y totalmente revisado y puesto al día, Madrid, Reus, I $947^{5}$.

Segura Riveiro, F., "Las servidumbres en el derecho de aguas", Revista de Derecho, 209, $200 \mathrm{I}$.

Silva Segura, E., Acciones, actos y contratos sobre cuota, Santiago, Jurídica de Chile, I985.

Solís de Ovando, J., "De la caducidad de las condiciones", Revista de Derecho y Jurisprudencia, 37, I940.

Somarriva Undurraga, M., Derecho sucesorio, iI, versión de René Abeliuk, Santiago, Jurídica de Chile, 20 r 6.

Somarriva Undurraga, M., Indivisión y partición, Santiago, Jurídica de Chile, 2002 , reimp. 2016.

Spano, G. y Caruso, S., "Le servitù prediali”, en Cendon, P. (ed.), Trattati, Milano, Giuffrè, 20I3.

Tavolari Oliveros, R. (dir.), Doctrinas esenciales, Santiago, Puntolex, 20 io.

Terré, F. y Simler, P., Droit civil: Les biens, Paris, Dalloz, 20 i4.

Tur Faúndez, M., "Mediante signo aparente (o por destinación del padre de familia)”, en Cerdeira, G. (ed.), Tratado de servidumbres, Madrid, La Ley, 20 I 5.

Varas Videla, E., De las servidumbres, tesis de grado para optar al título de licenciado, Santiago, Universidad de Chile, I925.

Velásquez Gómez, H. D., Estudio sobre obligaciones, Bogotá, Temis, 20 io.

Velásquez Jaramillo, L. G., Bienes, Bogotá, Temis, 2014.

Venezian, G., Usufructo, uso o habitación, R. Atard (trad.), t. II, Madrid, Revista de Derecho Privado, I928.

Vergara Blanco, A., Instituciones de derecho minero, Santiago, Abeledo-Perrot, 2010. 
Vergara Blanco, A., "Constitución de servidumbres a favor de instalaciones eléctricas”, Revista Chilena de Derecho, 25, 2, 1998.

Vergara Blanco, A. Derecho eléctrico, Santiago, Jurídica de Chile, 2004.

Vergara Duplaquet, C., "Normas por las cuales se rigen las servidumbres en materia de derecho de aguas", en Vergara Blanco, A. (dir.), Código de Aguas comentado: doctrina y jurisprudencia, Santiago, Abeledo-Perrot, 20 I I.

Vial del Río, V., Teoría general del acto jurídico, Santiago, Jurídica de Chile, 20 I I.

Vodanovic Haklicka, A., Tratado de los derechos reales, versiones de clases escritas de los profesores Arturo Alessandri y Manuel Somarriva, t. I, Santiago, Jurídica de Chile, 2016. 